\title{
Experimental investigation of various machining attributes and cost estimation during machining of hardened AISI 4340 steel with untreated and cryo treated cermet inserts
}

\author{
Anshuman Das ${ }^{1}$, Sudhansu Ranjan Das ${ }^{2,}$, Saroj Kumar Patel ${ }^{3}$, and Bibhuti Bhusan Biswal ${ }^{1}$ \\ ${ }^{1}$ Department of Industrial Design, National Institute of Technology, Rourkela 769008, Odisha, India \\ 2 Department of Production Engineering, Veer Surendra Sai University of Technology, Burla 768018, Odisha, India \\ ${ }^{3}$ Department of Mechanical Engineering, National Institute of Technology, Rourkela 769008, Odisha, India
}

Received: 12 June 2018 / Accepted: 5 November 2019

\begin{abstract}
Now-a-days due to growing demand of high precision components to attain high performances, hardened steels with hardness above $45 \mathrm{HRC}$ have numerous applications in automotive gear, machine tool and die industry because of their superior characteristics (high thermal stability, high indentation resistance, high abrasiveness, low ductility and high value of hardness to modulus of elasticity ratio). For this, higher tool life of cutting inserts cryogenic treatment is considered as the most prominent method but no substantial researches have been found concerning the impact of cryogenic treatment on cermet inserts, especially in turning of hardened steels. Therefore, in the present experimental investigation, the comparative assessment of various responses such as cutting force, flank wear, crater wear, chip morphology and surface roughness were carried out during machining of hardened steel with both untreated and cryo-treated cermet inserts under dry cutting condition. Lastly, the input variables were optimized using Response Surface Methodology (RSM) to evaluate the tool life for the economic analysis. The experimental result demonstrated that the uncoated deep cryotreated with tempered cermet insert delivered better results in comparison to other cermet inserts. According to cost analysis, uncoated and deep cryo-treated with tempered cermet insert was found to be the most cost saving among other cermet inserts at the optimum cutting condition.
\end{abstract}

Keywords: Hard turning / cryogenic treatment / machinability / cost analysis

\section{Introduction}

Quality, productivity and economic aspects of any machining process are influenced by tool life to a great extent. In general, the tool life is advisably influenced by the generation of high temperature at the tool-work and tool-chip interfaces during hard machining. In order to sustain at such high temperature hardness and wear resistance of the tool material must be high enough. In addition, due to the abrasion of cutting edge and rapid progressive wear on the rake and flank surfaces, the machining characteristics may be severely hampered. Various methodologies have been proposed by number of researchers and scientists for the enhancement of tool life, such as coating, heat treatment, application of divergent coolants, use of different types of tool geometries and cryogenic treatment. However, over the last few years, cryogenic treatment has been put through extensively by

\footnotetext{
* e-mail: das.sudhansu83@gmail.com
}

various researchers in the field of metal machining. Different types of cryogenic treatment such as indirect cryo-treatment of workpiece, tool materials and direct application of cryo-coolant on the machining surfaces have been executed by many researchers and scientists. Particularly, shallow and deep cryogenic treatment on cutting tool have shown an attention towards machinability improvement and cutting performance in machining performance of hard and difficult-to-cut materials due to improved wear resistance and cooling-lubrication effect. In the work of Thornton et al. [1], cryogenic treatment has reported to result in three significant changes in cobaltbonded tungsten carbides: (1) an increase in density of the cobalt binder ( $\nabla$-phase); (2) enlarged WC grains ( $\alpha$-phase) and; (3) finer $\eta$-phase particles which are also stabilised by cryogenic treatment. These changes could be expected to improve the corrosion resistance of the cobalt-binder and the thermal conductivity of the material due to a more contiguous WC grain structure. Although hard $\eta$-phase particles are often avoided in tungsten carbides to prevent premature fracture occurring, they may improve abrasive 


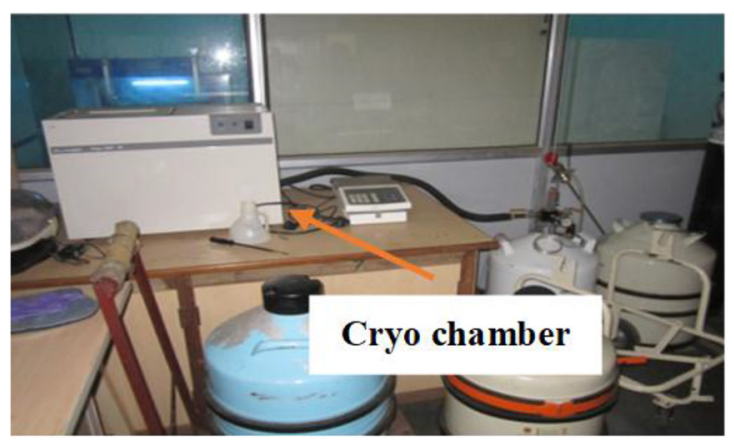

(a)

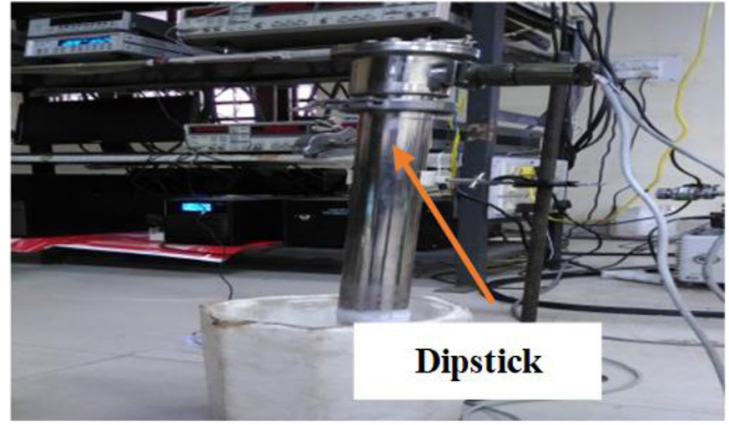

(b)

Fig. 1. Experimental setup for shallow cryogenic treatment (a), deep cryogenic treatment (b).

wear resistance and, if sufficiently refined and uniformly distributed, increase the toughness of cobalt-bonded tungsten carbides. The summarized results asserted that there was an improvement in the performances of cryotreated tools in comparison to the untreated tools. Extensive studies have been reported by employing cryogenic treatment on various cutting tool materials [217], to improve the wear resistance and tool life during machining of different workpiece materials (AISI 1040, 1045, 316, 4340, 5140, 52100, D3, H11, EN-24, EN-47, C-45, C-60, C-65, Ti6Al4V, Hastelloy C22) under dry and wet environments. Regardless various cryogenic treatment on cutting tools, numerous researchers have been reported to improve the heat extraction capability for various metal cutting applications [18-24] under the influence of cryogenic cooling.

From the literature review, it was unveiled that, most of the research works have been performed using steels such as mild steels, low carbon steels, medium carbon steels, high carbon steels, stainless steels and tool steels, etc. Still, specific research on medium carbon low alloy steel (i.e. AISI 4340) has not been performed so far. Many researches have been carried out using both coated and uncoated inserts mostly carbide, ceramic, CBN and PCBN. However, the same study has not been carried out on cermet inserts. Most of the researchers have performed the machining activities with deep cryogenically treated inserts. But, very few have opted shallow cryo- treatment process. Also, the cryogenic treatment with tempering has been proposed by very few researchers. In maximum cases, the temperature selected for the deep cryogenic treatment process was $-196^{\circ} \mathrm{C}$ and for shallow cryogenic treatment, the temperature was $-110^{\circ} \mathrm{C}$. Output responses like flank wear, surface roughness and cutting force have been analysed previously. However, substantial studies on chip morphology, crater wear and economic analysis have not been proposed by scientists and researchers using different untreated and cryo-treated inserts in the hard turning experiment. According to the above-mentioned research gap, the objective of the present work is focussed on studying the effect of both shallow and deep cryogenic treatment with tempering on output responses like flank wear, crater wear, surface roughness, cutting force and chip morphology while machining AISI 4340 alloy steel at 48
HRC using UCUT (uncoated untreated), UCSCT (uncoated shallow cryo-treated), UCSCTT, UCDCT and UCDCTT cermets. Further, the economic analysis has been performed using the above-mentioned cermet inserts.

\section{Experimental details}

The materials employed in the present experimental work, measurement techniques and the detailed experimental procedures, including cryogenic treatment are illustrated in this section.

\subsection{Shallow and deep cryogenic treatment of cermet inserts}

In both shallow and deep cryogenic treatment, the inserts were kept in a plastic container before placing in the cryochamber and the cryogenic dipstick as shown in Figure 1a and $\mathrm{b}$, respectively. This was done to prevent the direct contact of inserts with the liquid nitrogen to circumvent the possibility of thermal damage. The tempering operation was performed after shallow and deep cryogenic treatment to alleviate the residual stress induced during cryogenic treatment. In the current research work, uncoated cermet inserts were shallow and deep cryotreated followed by tempering. The entire procedure adopted for the above thermal treatments were summarized in the following steps and the cryogenic cycle diagrams were shown in Figure 2a and $\mathrm{b}$ for both shallow and deep cryo-treatment with tempering.

At first, the cermet samples were placed in the cryochamber. For shallow cryogenic treatment using a cooling rate of $1^{\circ} \mathrm{C} / \mathrm{min}$, the temperature was brought down to $-145^{\circ} \mathrm{C}$ from room temperature, i.e. $25^{\circ} \mathrm{C}$. After reaching the temperature mentioned above, the temperature was kept constant for $24 \mathrm{~h}$ for soaking. By the end of soaking period, the temperature was again raised to room temperature at the same rate. Tempering process was started after the final stage of the cryogenic cycle, where the inserts were kept in a furnace and heated to a temperature of $145^{\circ} \mathrm{C}$ with a same rate. After attaining the temperature, it was kept constant for $7 \mathrm{~h}$. Then finally, the temperature was brought down to the room 

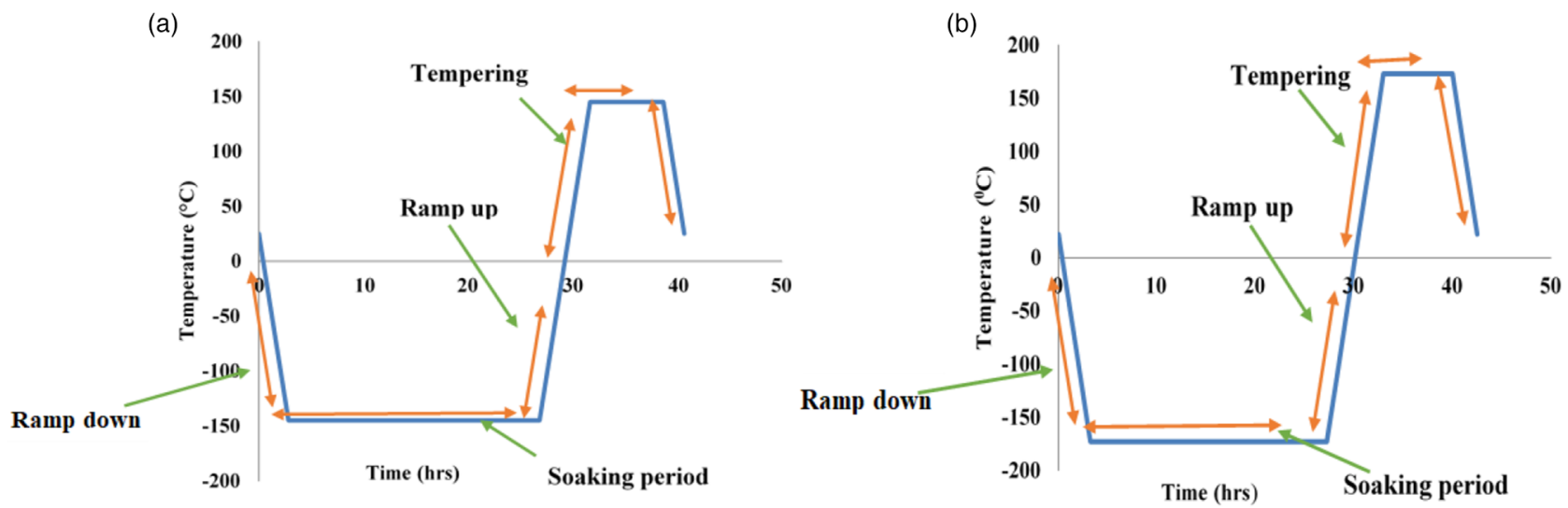

Fig. 2. Procedure followed for (a) shallow; (b) deep cryo treatment with tempering.

temperature, at the same rate i.e. $1^{\circ} \mathrm{C} / \mathrm{min}$. For deep cryogenic treatment, the same procedure was adopted but the temperatures selected were $22^{\circ} \mathrm{C}$ (the room or initial temperature), $-173^{\circ} \mathrm{C}$ (final temperature) and $173^{\circ} \mathrm{C}$ (temperature for tempering cycle). Also, in deep cryogenic treatment, the cryogenic chamber was replaced by cryogenic dipstick, which was immersed in liquid nitrogen. The electronic temperature controller controlled the temperature. The tempering cycle adopted in deep cryotreatment was the same for the shallow cryogenic treatment.

\subsection{Experimental procedure}

In the present experimental work, experimental runs were carried out according to $\mathrm{L}_{9}$ orthogonal array, i.e. three factors with three levels for different uncoated inserts. Three factors such as the cutting speed, the feed and depth of cut were considered and their effects on the responses like cutting force, flank wear, crater wear, chip morphology and surface roughness were observed. Before the actual machining operation, the workpiece was first centered, and then the rust layer was removed from the outer surface of the workpiece for the alleviation of any end results of inconsistency on the responses. Each experimental run was carried out for a machining length of $200 \mathrm{~mm}$.

\subsection{Design of experiment (L9 Taguchi's orthogonal array)}

Taguchi has envisaged a reliable method of conducting the Design of Experiments (DOE) in any manufacturing process, which is based on well-defined guidelines. The main purpose of DOE technique is to deliver qualitative products with less expense. With this aim, Taguchi proposed a new technique for DOE entangled with an orthogonal array called Taguchi's orthogonal array [25]. The method of the orthogonal array was preferred for standardization of input variables influencing the operational procedure and to select their levels for alteration. In a factorial design, all possible amalgamation of input
Table 1. Experimental layout of Taguchi's L ${ }_{9}$ orthogonal array.

\begin{tabular}{llllllll}
\hline \multirow{2}{*}{ Run } & \multicolumn{3}{c}{ Coded values } & & \multicolumn{3}{c}{ Actual settings } \\
\cline { 2 - 3 } \cline { 6 - 7 } & $v$ & $f$ & $d$ & & $v$ & $f$ & $d$ \\
\hline 1 & 1 & 1 & 1 & & 80 & 0.05 & 0.1 \\
2 & 1 & 2 & 2 & & 80 & 0.10 & 0.2 \\
3 & 1 & 3 & 3 & & 80 & 0.15 & 0.3 \\
4 & 2 & 1 & 2 & & 100 & 0.05 & 0.2 \\
5 & 2 & 2 & 3 & & 100 & 0.10 & 0.3 \\
6 & 2 & 3 & 1 & & 100 & 0.15 & 0.1 \\
7 & 3 & 1 & 3 & & 120 & 0.05 & 0.3 \\
8 & 3 & 2 & 1 & & 120 & 0.10 & 0.1 \\
9 & 3 & 3 & 2 & & 120 & 0.15 & 0.2 \\
\hline
\end{tabular}

variables with their levels are usually chosen, whereas in Taguchi's orthogonal array only a few sets of combinations of input parameters which influences the results much with their corresponding levels, are selected. So, by adopting the Taguchi's orthogonal array technique, better results can be attained with less cost and time. In the present experimental work, experimental runs were carried out according to $\mathrm{L}_{9}$ orthogonal array, i.e. three factors with three levels for different uncoated inserts. Table 1 shows the well-planned experimental condition details based on Taguchi's $\mathrm{L}_{9}$ orthogonal array design of experiments (DOEs), which explains the sequence of experimentation.

\subsection{Workpiece material}

For the present experimental work, AISI 4340 steel was chosen as workpiece material having diameter $50 \mathrm{~mm}$ and length $600 \mathrm{~mm}$ (round bar). The chemical composition of the specimen in wt. \% was examined using Spectro metal analyser and is presented in Table 2. The steel utilized in this study was a medium carbon, low alloy and high 
Table 2. Constituents of the workpiece material in wt. $\%$.

\begin{tabular}{llllllll}
\hline Elements & $\mathrm{C}$ & $\mathrm{Ni}$ & $\mathrm{Cr}$ & $\mathrm{Mo}$ & $\mathrm{Mn}$ & $\mathrm{Si}$ & $\mathrm{Fe}$ \\
\hline Weight percentage & 0.397 & 1.55 & 0.9 & 0.275 & 0.77 & 0.339 & 95.762 \\
\hline
\end{tabular}

Table 3. Tool holder geometry.

\begin{tabular}{lllllll}
\hline Tool holder signature & $\begin{array}{l}\text { Clearance } \\
\text { angle }\end{array}$ & $\begin{array}{l}\text { Back rake } \\
\text { angle }\end{array}$ & $\begin{array}{l}\text { Entering } \\
\text { angle }\end{array}$ & $\begin{array}{l}\text { Point } \\
\text { angle }\end{array}$ & $\begin{array}{l}\text { Nose } \\
\text { radius }\end{array}$ & $\begin{array}{l}\text { Side rake } \\
\text { angle }\end{array}$ \\
\hline Angle recommended & $0^{\circ}$ & $-6^{\circ}$ & $75^{\circ}$ & $90^{\circ}$ & $0.8 \mathrm{~mm}$ & $-6^{\circ}$ \\
\hline
\end{tabular}

strength steel. Due to high impact or shock resistance, wear and abrasive resistance, this material is preferred for manufacturing of different automobile as well as structural components. The material was heat treated with different heat treatment processes like austenitizing, quenching and tempering. After completion of the entire process, hardness of the specimen was increased from $18 \mathrm{HRC}$ to $48 \mathrm{HRC}$.

\subsection{Insert and tool holder}

In the present experimental analysis, uncoated cermet insert was used. This insert was procured from Taegutec company having grade CT3000 specified as SNMG 120408. The grade of chip breaker geometry associated with this insert was FG, preferred in finishing and semi-finishing operation. This particular insert was selected because of its superior wear resistance, toughness, thermal conductivity and low adhesion. The insert was mounted on a PSBNR2020K12 designated tool holder with the following cutting geometries, as shown in Table 3.

\subsection{Machine tool and measuring instruments}

Straight turning operation was carried out in dry cutting condition on a highly rigid and precision lathe (Manufacturer: HMT India Ltd.) having a maximum spindle speed of $2040 \mathrm{rpm}$ and a power of $11 \mathrm{~kW}$. To measure the machining forces along three perpendicular directions, Kistler threedimensional dynamometer was used. The width of flank wear after each experimental run was measured using advanced optical microscopy of model 100HD-3D (Make: Carl Zeiss) with a range of magnification from $10 \times$ to $50 \times$ whereas, the morphological study of the flank surface was accomplished using SEM (Make: JEOL JSM- 6084 LV). Chip morphological study was accomplished using SEM and the identifications of wear patterns on the rake surface of the inserts were also accomplished by the SEM. The surface roughness parameter (Ra) was measured using a Mitutoyo roughness tester. Figure 3 shows the schematic layout of machining setup, experimental procedure followed and the equipment used for machinability investigation.

\section{Results and discussion}

\subsection{Microstructural analysis of untreated, cryo-treated and cryo-treated with tempered inserts}

From Figure 4a, it was found that the volume of $\eta$ phase carbides present was lower than that of $\alpha$ phase carbides. Due to non-cryogenic treatment secondary carbide particles were not formed. The uniformly distributed coarse grain structure (larger components) was also found. From Figure $4 \mathrm{~b}$, it was discovered that secondary particles precipitated uniformly in the substrate and they formed on a large scale. In cryo-treated inserts, fine grain structure (smaller components) was observed when compared to untreated inserts. The hardness and wear resistance of inserts were improved because of formation of $\eta$ phase carbides. The SEM image of UCSCTT shown in Figure 4c revealed that better precipitation and uniform distribution of $\eta$ phase carbide particles was due to tempering. However, due to tempering the volume of that particular phase of carbide was diminished as compared to cryotreated inserts. Same results were observed in case of UCDCT \& UCDCTT cermet inserts shown in Figure 4d and e.

\subsection{EDX analysis}

Hardness and wear resistance of cermet inserts were improved after cryogenic treatment. This was due to the diminution and compaction of cobalt or binder phase as well as the increment of carbon percentage both in weight and atomic scale. This was evident from the EDX analysis of uncoated cermet, before the cryogenic treatment, the weight percentage and atomic percentage of cobalt were 5.40 and 6.10 , but after the cryogenic treatment, the weight and atomic percentage were diminished to 1.01 and 3.08 respectively, as shown in Figure $5 \mathrm{a}$ and $5 \mathrm{~b}$, and was mentioned in Table 4 as given below. During cryogenic treatment, different carbide particles or carbide fillers of various phases such as $\alpha, \bigotimes, \gamma$ and $\eta$ phase carbides are normally formed. This was due to the alteration of carbon percentage after the cryogenic treatment, as observed from the EDX graph. It was observed after cryogenic treatment, the weight and atomic percentage of carbon was enhanced 


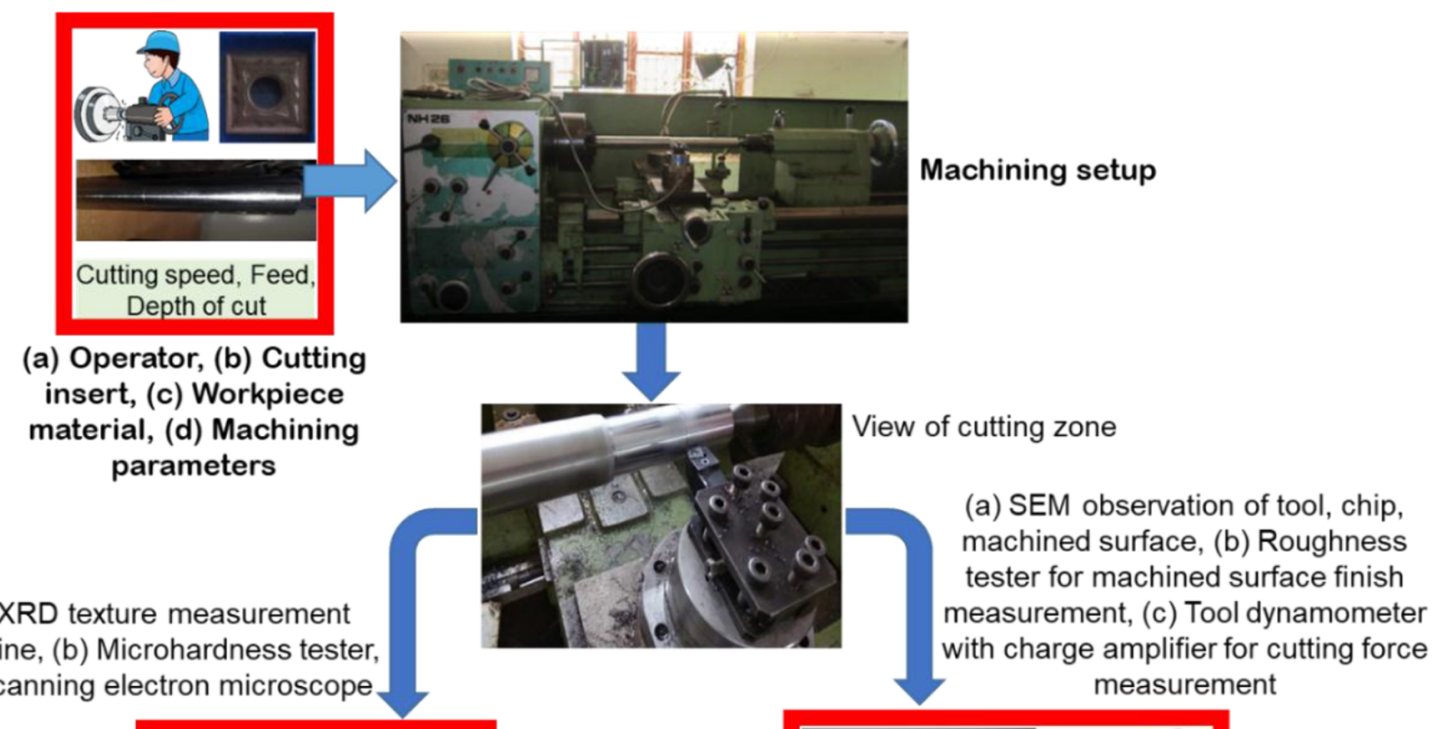
(erder,

(c) Scanning electron microscope
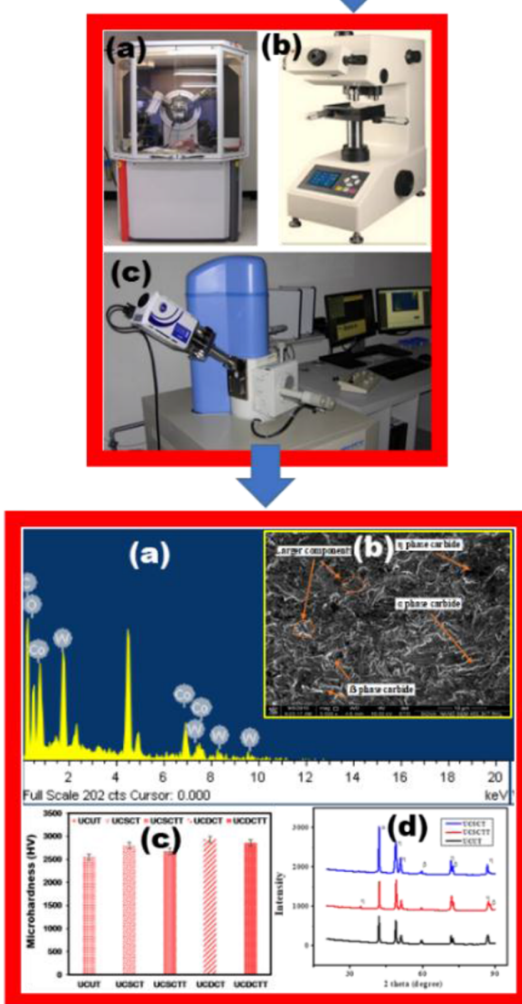

Characterization of cutting tool before and after cryogenic treatment:

(a) Microstructural analysis, (b) EDX

analysis, (c) Microhardness analysis,

(d) XRD analysis

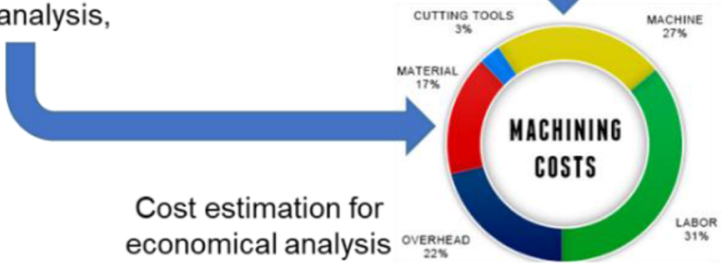

Fig. 3. Simplistic layout of the present experimental setup.

Analysis on cutting force, tool wear mechanism, chip and machined surface morphology for comprehensive understanding of cutting process using untreated and understanding of cutting process using
cryo-treated cermet tool
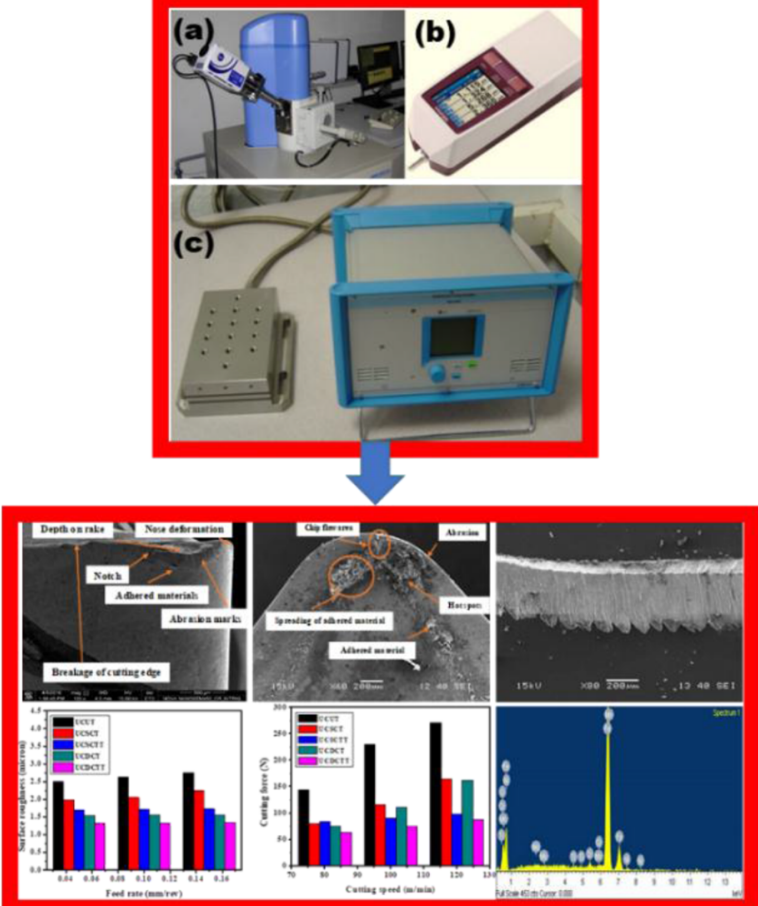


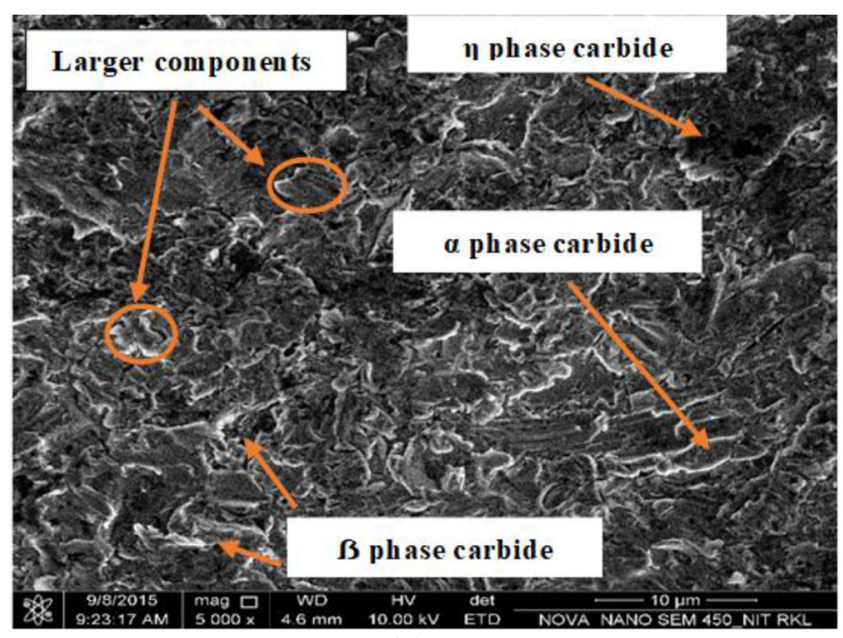

(a)

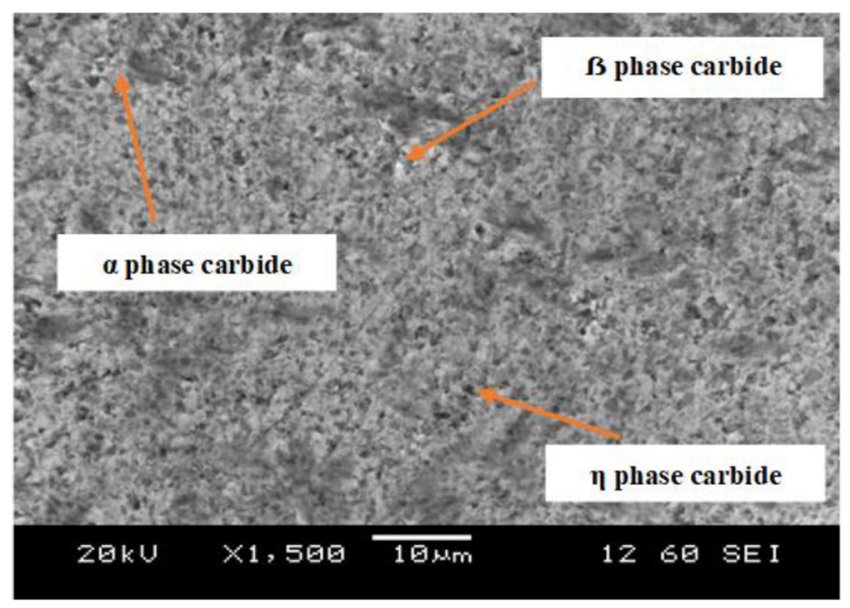

(c)

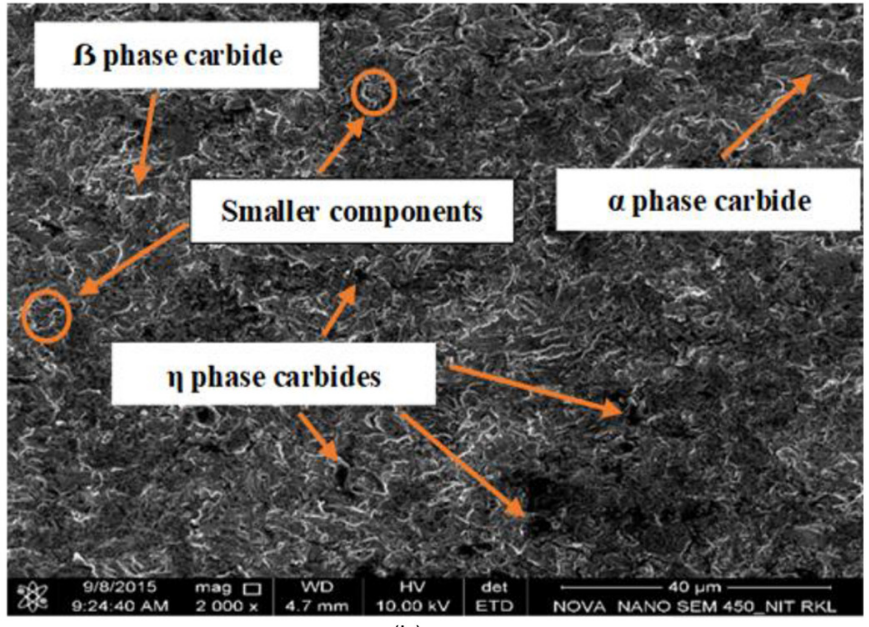

(b)

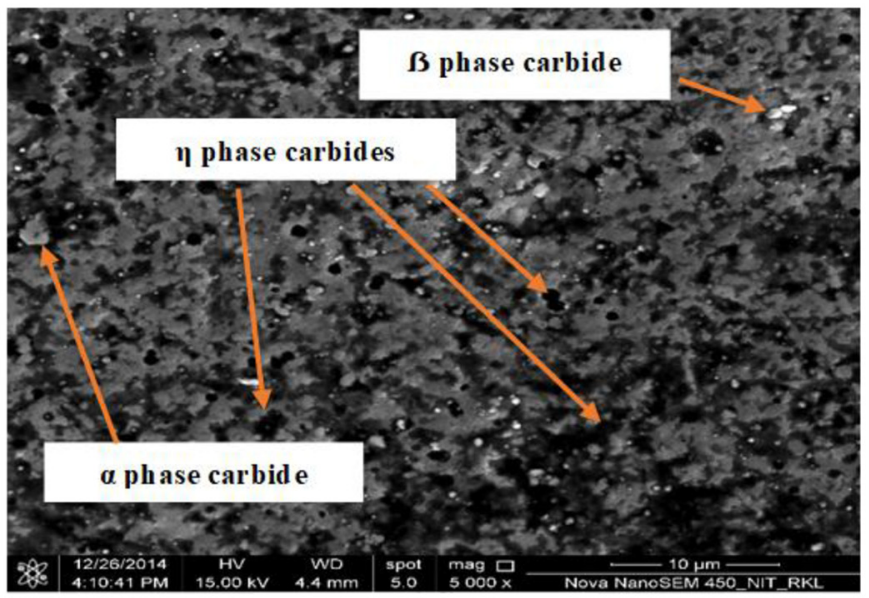

(e)

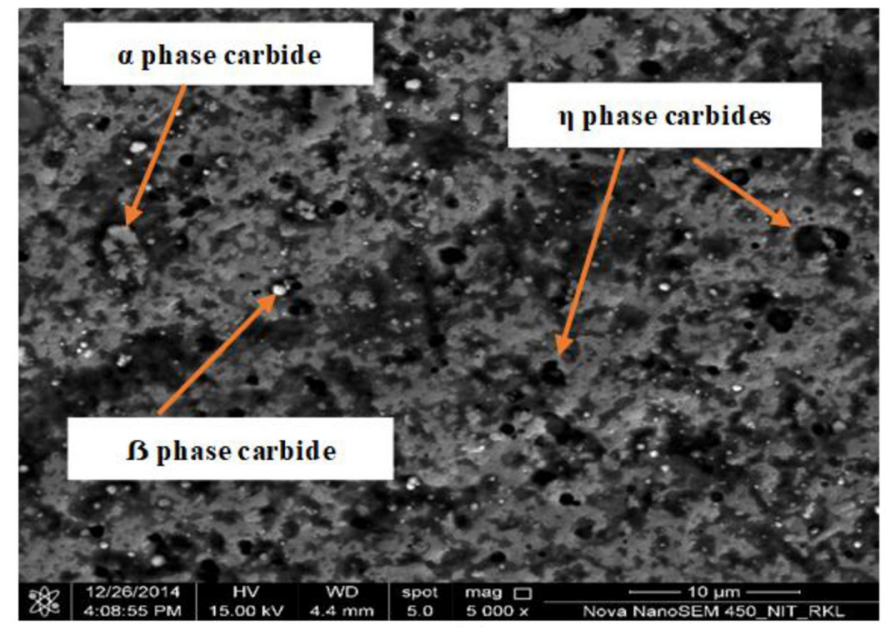

(e)

Fig. 4. SEM images of cermet inserts: (a) UCUT, (b) UCSCT, (c) UCSCTT, (d) UCDCT, and (e) UCDCTT.

from 11.52 to 18.66 and 63.84 to 75.64 percentage, respectively. In cryogenic treatment, hardness and wear resistance of a material increased. Because in this treatment, tool material is indirectly contact with the liquid nitrogen at a very low temperature. So different carbide phases precipitated like, $\alpha, \beta$ and $\gamma$ phases. But the most effective one is $\gamma$ phase in the material matrix during the treatment, which imparts very high hardness and wear resistance. However, after tempering the weight and atomic percentage of cobalt increased and weight and 


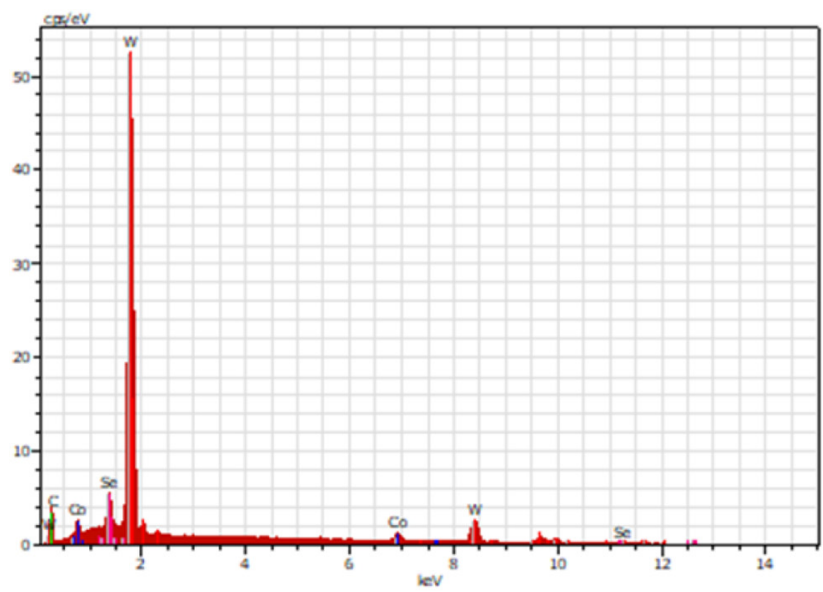

(a)

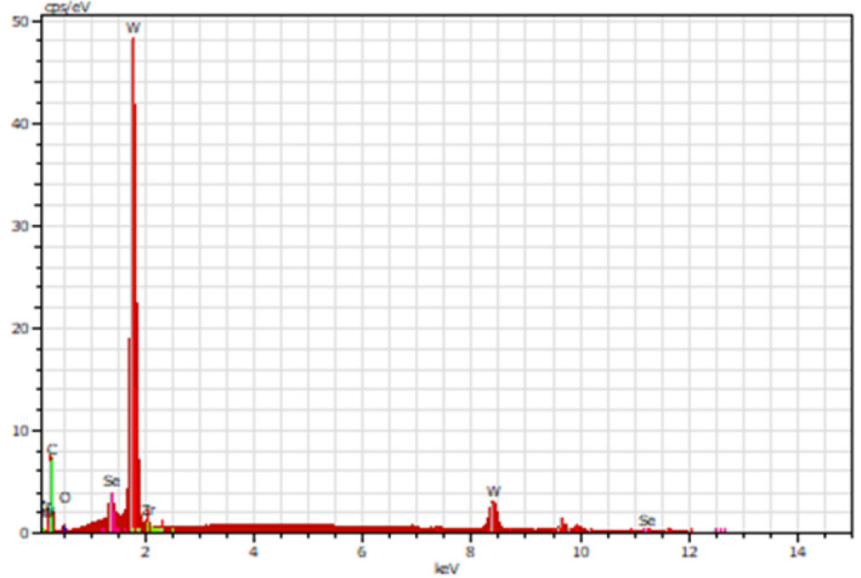

(b)

Fig. 5. Elemental analysis of uncoated cermet: (a) before cryogenic treatment, and (b) after cryogenic treatment.

Table 4. Constitute elements of different cermet inserts before and after cryo-treatment.

\begin{tabular}{|c|c|c|c|c|c|c|c|c|c|c|}
\hline Elements & \multicolumn{2}{|c|}{$\begin{array}{l}\text { Before cryogenic } \\
\text { treatment }\end{array}$} & \multicolumn{2}{|c|}{$\begin{array}{l}\text { After cryogenic } \\
\text { treatment }\end{array}$} & \multicolumn{2}{|c|}{$\begin{array}{c}\text { Shallow cryogenic } \\
\text { treatment } \\
\text { with tempering }\end{array}$} & \multicolumn{2}{|c|}{$\begin{array}{c}\text { Deep } \\
\text { cryogenic } \\
\text { treatment } \\
\end{array}$} & \multicolumn{2}{|c|}{$\begin{array}{l}\text { Deep cryogenic } \\
\text { treatment with } \\
\text { tempering }\end{array}$} \\
\hline W & 83.01 & 30.06 & 80.33 & 21.27 & 81.39 & 27.11 & 71.38 & 17.78 & 76.394 & 19.62 \\
\hline $\mathrm{C}$ & 11.52 & 63.84 & 18.66 & 75.64 & 16.69 & 72.32 & 27.33 & 91.02 & 24.49 & 84.631 \\
\hline $\mathrm{Se}$ & 0.00 & 0.00 & 0.00 & 0.00 & 0.00 & 0.00 & 0.00 & 0.00 & 0.00 & 0.00 \\
\hline
\end{tabular}

atomic percentage of carbon reduced. The variations in weight and atomic percentage of carbon and cobalt for different cermet inserts were tabulated below in Table 4 .

\subsection{XRD analysis}

Before and after the cryogenic treatment, with the help of XRD texture measurement machine XRD analysis was done to ensure whether there were any physical changes occurred or not, in all three cases, i.e. untreated, cryotreated (both shallow and deep) and cryo-treated with tempering. There were three phases of carbides like $\alpha, \beta$ and $\eta$ phase present. A phase consists of tungsten carbide (WC), $\beta$ phase consists of binder phase and $\eta$ phase consists of multiple carbides (one phase from the binder and another phase from tungsten). In cryogenically treated inserts (both shallow and deepcryo treatment), $\alpha, \beta$ and $\eta$ phase carbides were present with high intensities compared to untreated and cryo-treated with tempered inserts. And the high volume of $\eta$ phase carbide was present in cryotreated inserts as compared to treated with tempered one, whereas the minimum volume of $\eta$ phase carbide was present in untreated inserts as shown in Figure 6a and b. As the selected grade contains cobalt and tungsten, $\gamma$ phase carbide was considered to be insignificant. The elements like $\mathrm{TiC}$, TiN, and $\mathrm{TaC}$ were found absent according to EDX analysis.

In the present study, the XRD technique is used to measure the surface residual stresses to depths of up to $30 \mu \mathrm{m}$ by calculating the strain from the diffraction peak positions and also measurements can be made at depths up to $1 \mathrm{~mm}$ when combined with layer removal. Bruker D8 Advance Eco is used for residual stress measurement, providing full-sized goniometer class powder XRD under ambient and non-ambient conditions. In practice, a metal powder with no stress is measured first to set the angular scale of the detectors for a certain material. Stress is then calculated by measuring lattice distance with multiple tilt angles. The accuracy of the technique is heavily dependent upon good surface preparation and grain size/texture. During stress measurements, the X-ray beam penetrates the material and diffracts both in the distorted layer. Therefore, the surface of the cryo-treated metal characterized by these multiple stressed layers allows applying the methodology of diffraction line simulation for analysis of residual stress state in the materials. According to this methodology, the total diffraction profile represents the sum of profiles reflected separately by sequence of superficial layers with heterogeneously distributed residual stresses. The values of induced stress for various uncoated 


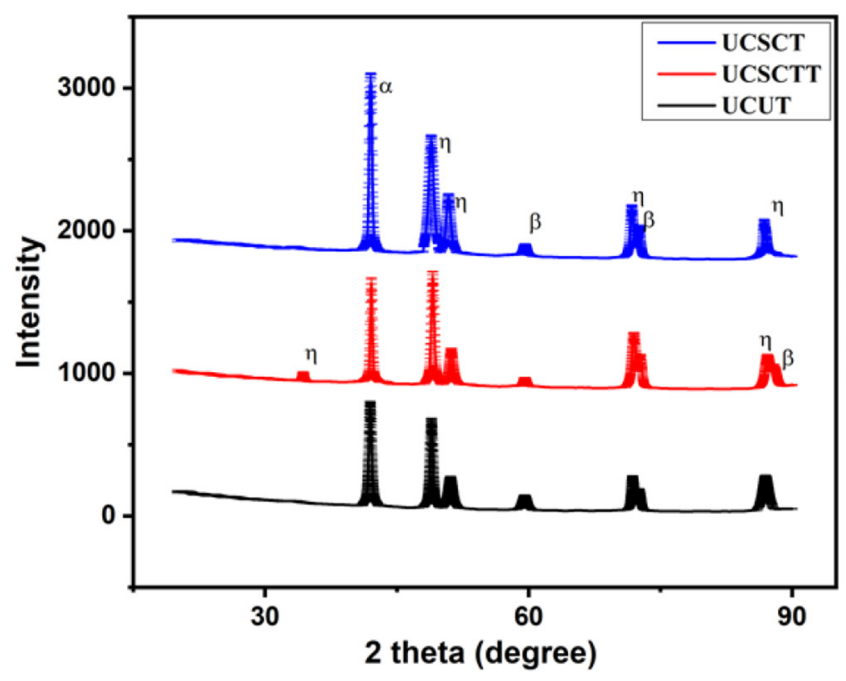

(a)

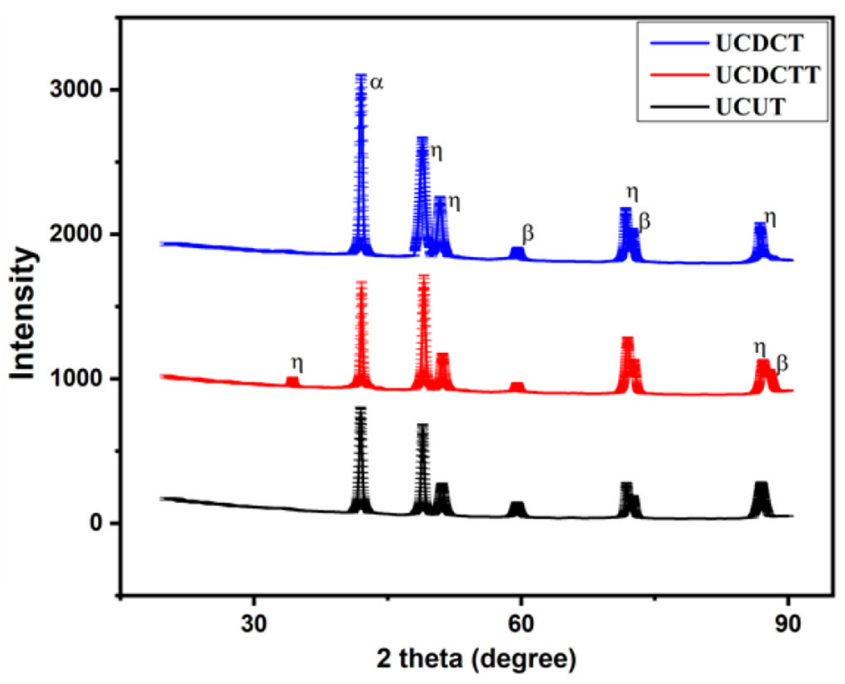

(b)

Fig. 6. XRD analysis of cermet inserts: (a) UCUT, UCSCT, UCSCTT; (b) UCUT, UCDCT, UCDCTT.

Table 5. Residual stress measurement for various inserts.

\begin{tabular}{llllll}
\hline Type of inserts & UCUT & UCSCT & UCSCTT & UCDCT & UCDCTT \\
\hline Residual stress in $\mathrm{MPa}$ & 1144.4 & 1460.8 & 1075.6 & 1806.3 & 1369.08 \\
& (Tensile) & (Compressive) & (Compressive) & $\begin{array}{l}\text { (Compressive) } \\
\text { (Compressive) }\end{array}$ \\
\hline
\end{tabular}

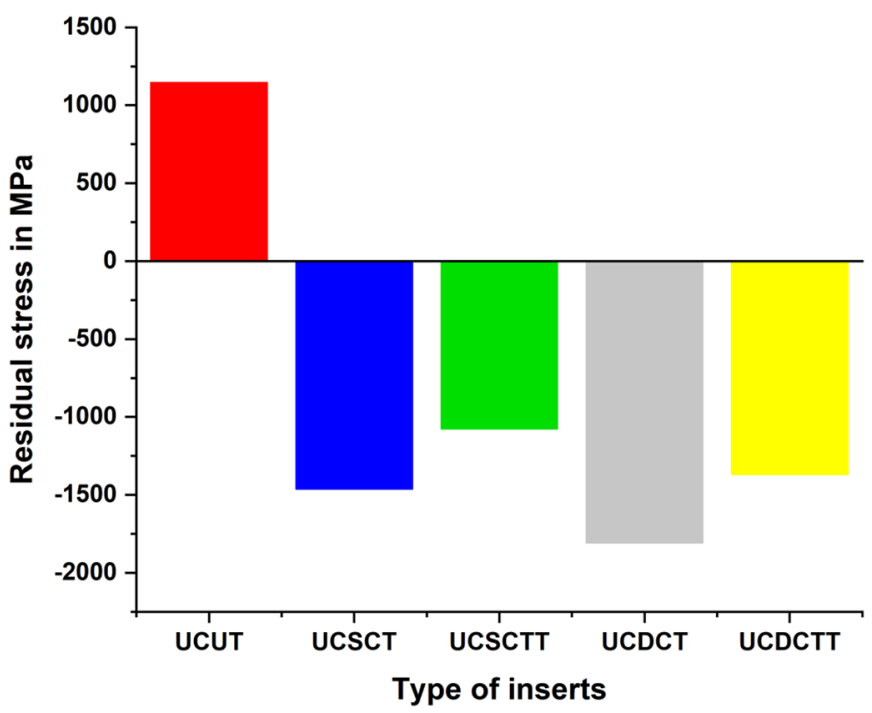

Fig. 7. Residual stress of various untreated and cryo-treated cermet inserts.

cermets are shown in Table 5. It is observed that, in case of UCUT insert, tensile stress was present, but after the cryogenic treatment, compressive stress is developed. The highest value of compressive residual stress found in UCDCT insert compared to other three cryo-treated (UCSCTT, UCDCTT, UCSCT) inserts is pictorially presented in Figure 7. However, the value of induced residual stress reduced substantially after tempering.

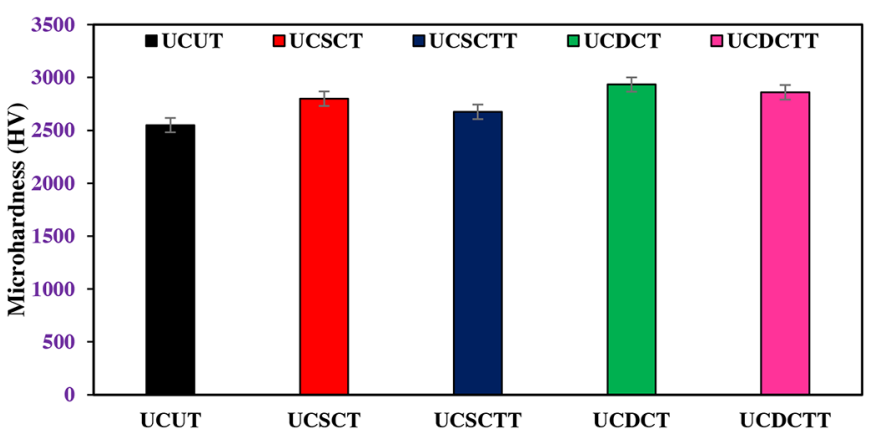

Fig. 8. Microhardness of cermet inserts.

\subsection{Microhardness analysis}

In this present experimental investigation, microhardness of cutting inserts, an indispensable mechanical property, was evaluated and studied in details. Microhardness normally gets influenced by the phase change and microstructural alteration of a material. Microhardness of the inserts was measured with Vickers microhardness tester. Figure 8 illustrated the microhardness of different cermet inserts. Because of shallow and deep cryogenic treatment, there was an increment in the hardness of 8.92 and $13.09 \%$, respectively. The carbon redistribution (segregation and clustering) responsible for low-temperature conditioning of martensite can occur only during long soaking. The size of the carbides is reduced and the carbide 


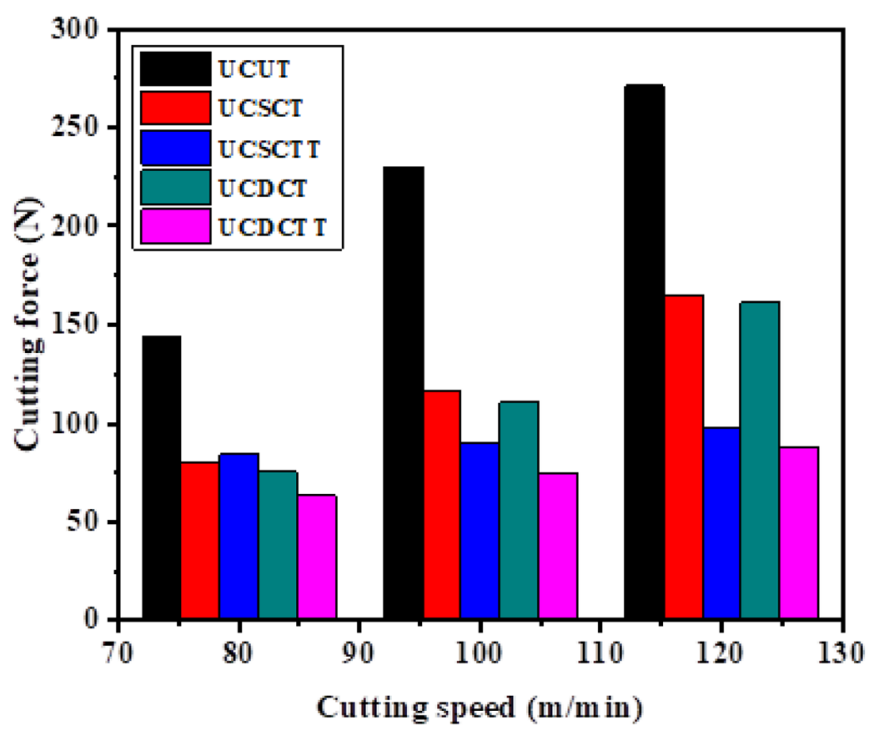

Fig. 9. Effect of cutting speed on cutting force.

count is also increased. This leads to increase in hardness $[1,12]$. In case of tempering, reduced the hardness of both shallow and deep cryo-treated inserts about $4.46 \%$ and $2.48 \%$, respectively. The development of stress relaxation generates crystal defects by means of cooling the martensite. This is the main reason for the reduction in hardness, as reported in the work of Senthilkumar [26].

\subsection{Effects of machining parameters on the responses}

Figure 9 shows the effect of cutting speed on main cutting force for untreated and cryo-treated cermet inserts. Cutting force increased with the increment of cutting speed. The highest value of cutting force was observed for UCUT insert, while the least cutting force appeared in case of UCDCTT insert. The tool geometry highly influenced both the flank wear and machining force. In the current study, square inserts having point angle $90^{\circ}$ and entering or approach angle $75^{\circ}$ were considered. Due to high magnitude of point angle, the larger contact area between cutting edge and workpiece was established. Therefore, high cutting force was exerted by these inserts. Similarly, due to the entering angle, vibration was developed during machining, for which both cutting force and flank wear increased. When flank wear was increased, cutting force was greatly affected and changed drastically as a result of temperature rise. UCUT inserts exhibited highest flank wear and therefore maximum cutting force was developed as compared to other inserts, as shown in Figure 10a. Surface roughness increased with the increment of cutting speed because there was an enhancement of cutting force with speed for all inserts. The higher cutting force was observed at high cutting speed because of maximum vibrating force. As a result, surface roughness increased almost for all types of inserts. There was a mixed relationship between the depth of cut and surface roughness, whereas with feed, surface roughness increased.
Flank wear grew rapidly as cutting speed increased, because, with cutting speed, temperature increased simultaneously, which was responsible for tool wear and plastic deformation. At high cutting speed, high temperature was developed near the cutting edges of the inserts, but because of lower thermal conductivity for UCUT insert, the tool strength was reduced drastically compared to cryo-treated inserts. So, more flank wear was observed in case of UCUT insert in comparison to other inserts as shown in Figure 10b. The surface roughness of the specimen was also affected with the increment of flank wear for all cermet inserts. Due to maximum flank wear, the highest value of roughness was obtained for UCUT insert and lowest value was for UCDCTT insert $[2,6,16]$, as shown in Figure 10c.

\subsection{Flank wear analysis of cermet inserts using SEM}

Various types of wear patterns were observed in case of UCUT insert as shown in Figure 11a i.e. chipping or breakage of cutting edge, nose wear, abrasion, adhesion and notch. Because of non-cryogenic treatment, the hardness and wear resistance of the insert could not be improved. This might be the main reason for the types of wear mechanisms quoted above. The notch was formed due to plastic deformation of the cutting edge. Due to excessive mechanical loading during machining, edge chipping occurred. Deep abrasion marks were observed on the flank face because of the presence of hard constituents in the specimen due to heat treatment. At the nose surface, plastic deformation was noticed because of thermal softening. This might be due to low thermal conductivity. Chip materials were adhered to both the rake and flank face of the insert due to its tenacious nature. Due to this tenacious nature, wear with higher depth was observed at the tool rake face.

In case of UCSCT cermet insert, hardness, wear resistance and toughness were improved due to shallow cryogenic treatment. As a result, less flank wear with thin abrasion marks were observed as shown in Figure $11 \mathrm{~b}$. However, at the region of the main cutting edge, brittle or catastrophic failure was observed. Because of the disruption of various phases of carbide particles from the tool substrate, the other wear mechanisms such as a notch, plastic deformation was not found in case of the shallow cryo-treated insert.

On account of tempering, appropriate precipitation and better distribution of $\eta$ phase carbides were noticed in the SEM image of UCSCTT cermet insert (Fig. 4c), for which the excessive hardness of the insert was reduced but toughness and wear resistance were improved. As a result, very less flank wear and reduction of damaged surface appeared at the main cutting edge as shown in Figure 11c. Whereas, due to the decrement of hardness, plastic deformation occurred at the nose region, which can be referred, as notch wear. The decrement of damaged region was observed due to less residual stress concentration and vibration of cutting tool. In addition, due to the reduction of excessive hardness and increment of wear resistance and toughness, the impact of chip hammering was substantially diminished. 

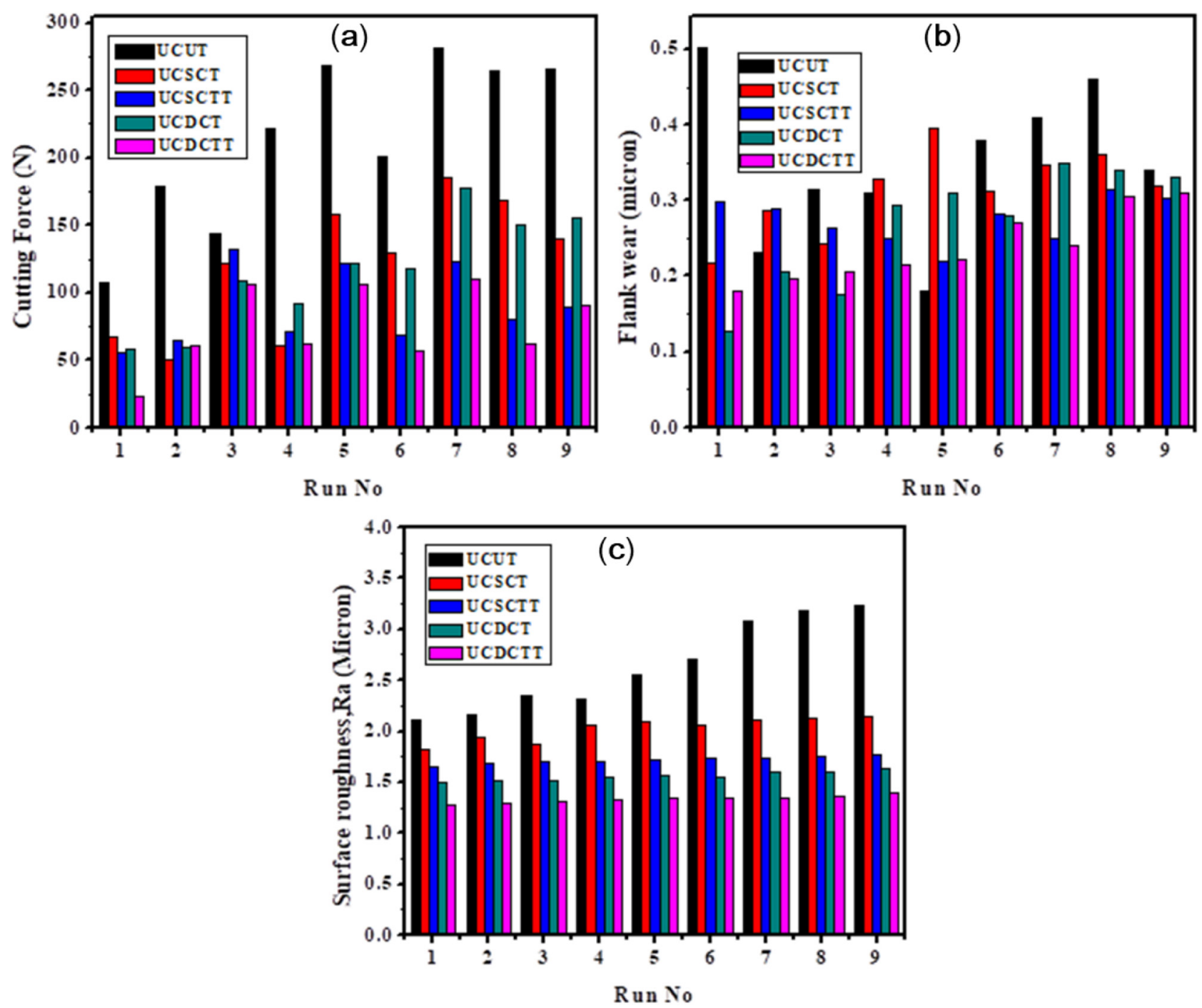

Fig. 10. Development as well as growth of cutting force, flank wear and surface roughness using various cermet inserts.

From the experimental data, it was observed that hardness and wear resistance of cermet insert were substantially increased due to deep cryogenic treatment because of the formation of $\eta$ phase carbide particles. As a result, very less wear was observed on the flank surface of UCDCT cermet insert. In addition, due to the improvement in thermal conductivity, thermal cracks, damages and softening of cutting edge were not detected. Whereas, there was a damaged region found at the main cutting edge due to the enhancement of excessive hardness and brittleness for deep cryogenic treatment. As the high volume of $\eta$ phase carbide was precipitated along the tool substrate owing to deep cryogenic treatment, the compressive residual stress was formed. This local stress concentration might hamper the tool performance during machining in terms of edge breakage. Another reason for the damaged region at the cutting edge was due to clashing of hard chips with the cutting edge that formed during machining, called chip hammering.

As seen from the SEM image of UCDCTT insert (Fig. 4e), there was a decrement in the volume of $\eta$ phase carbides due to tempering. The hardness of the insert was reduced, but wear resistance and toughness were significantly improved [13,17]. Minimum wear rate for this particular insert was observed. Due to high wear resistance and toughness, smooth wear pattern could be seen at the flank surface of the insert as shown in Figure 11e. Also, because of better wear resistance of UCDCTT insert, a very narrow fractured region on the rake face was noticed and abrasive wear due to hard chip flow on the rake surface was minimized. The other wear mechanisms such as plastic deformation, notch wear, thermal softening and chipping were not found for the increment of thermal conductivity, high hot hardness and reduction of residual stress concentration due to tempering.

\subsection{Analysis on crater wear}

Minimum wear on the rake surface was observed for uncoated and cryo-treated with tempered insert compared to untreated and cryo-treated insert, which was shown in Figure $12 \mathrm{a}-\mathrm{c}$. The crater wear mainly occurred due to 


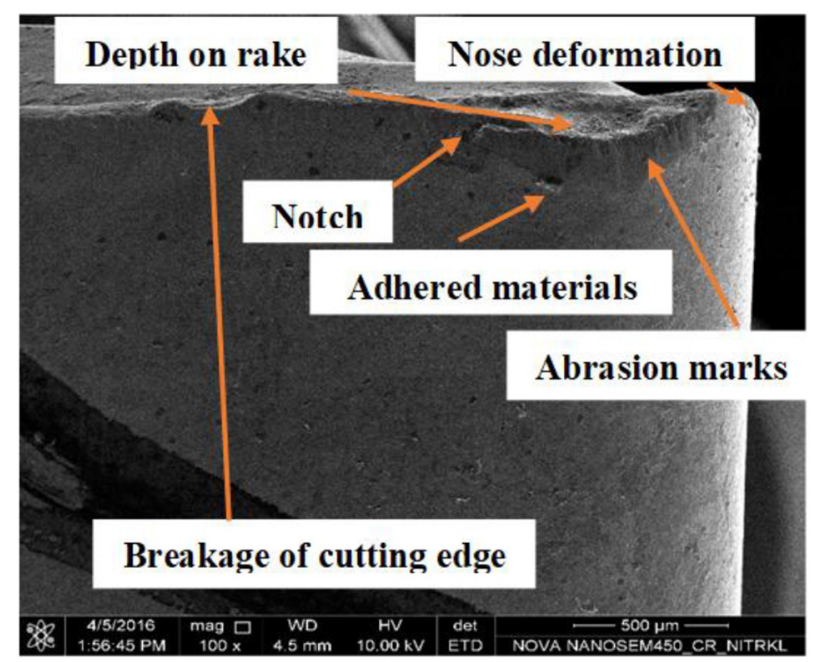

(a)

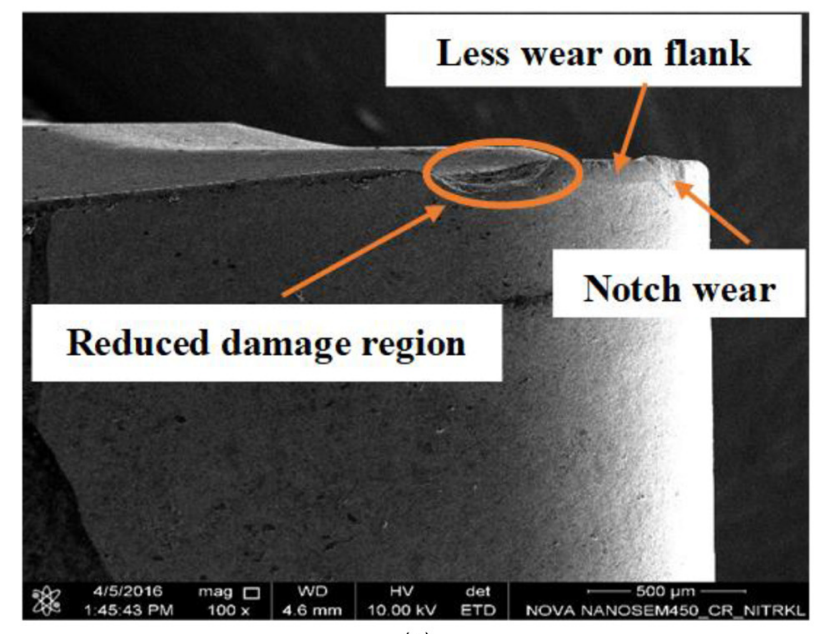

(c)
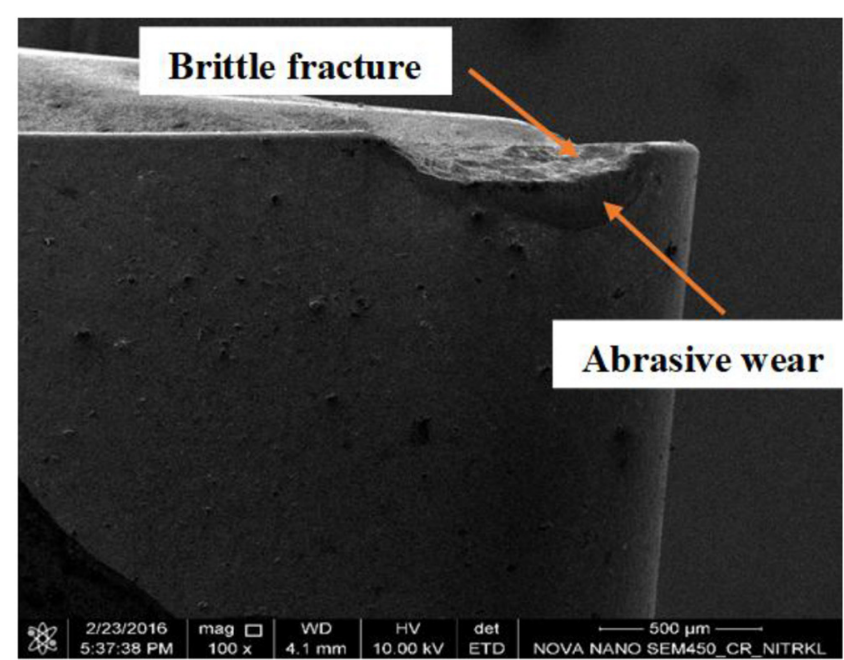

(b)

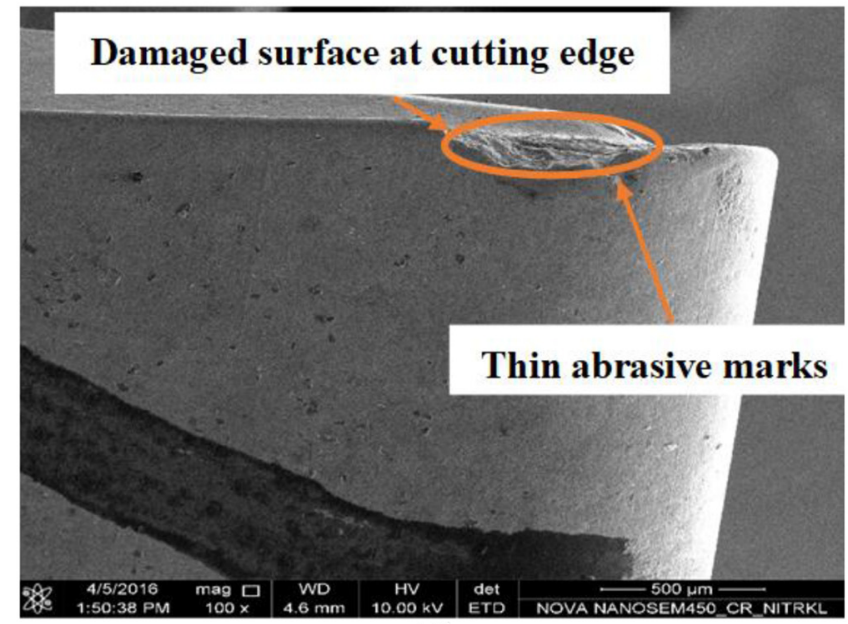

(d)

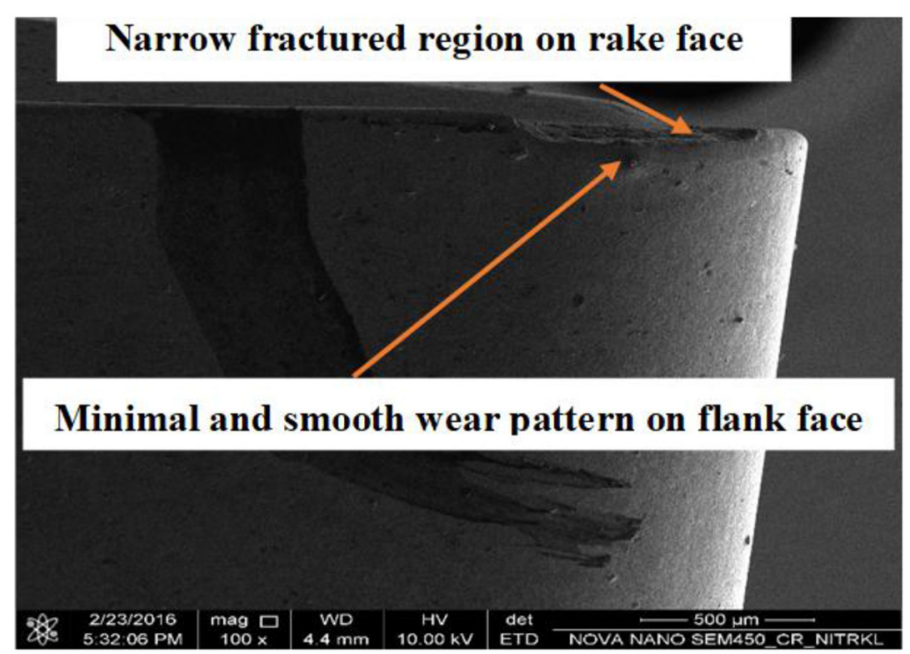

(e)

Fig. 11. Flank wear of cermet inserts: (a) UCUT, (b) UCSCT, (c) UCSCTT, (d) UCDCT, and (e) UCDCTT. 


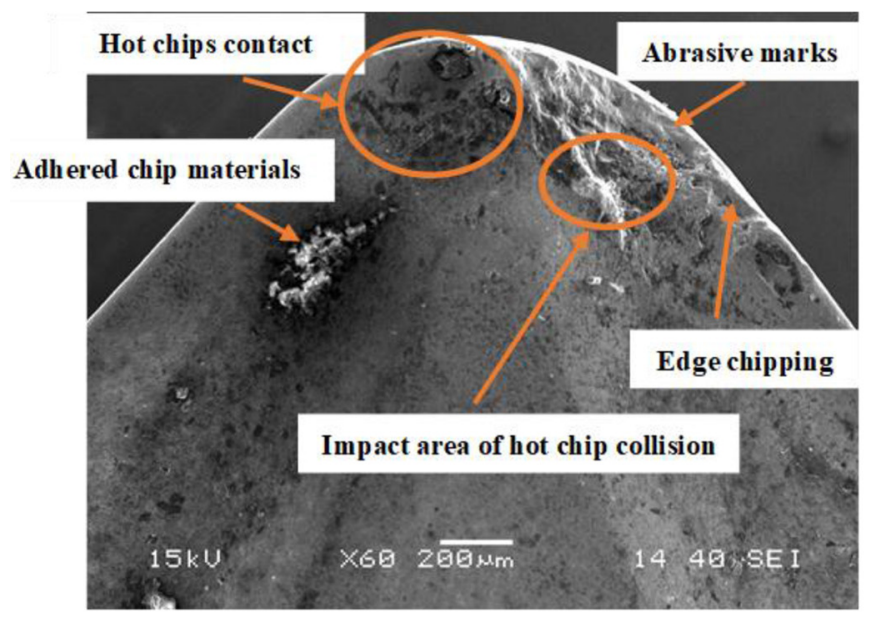

(a)
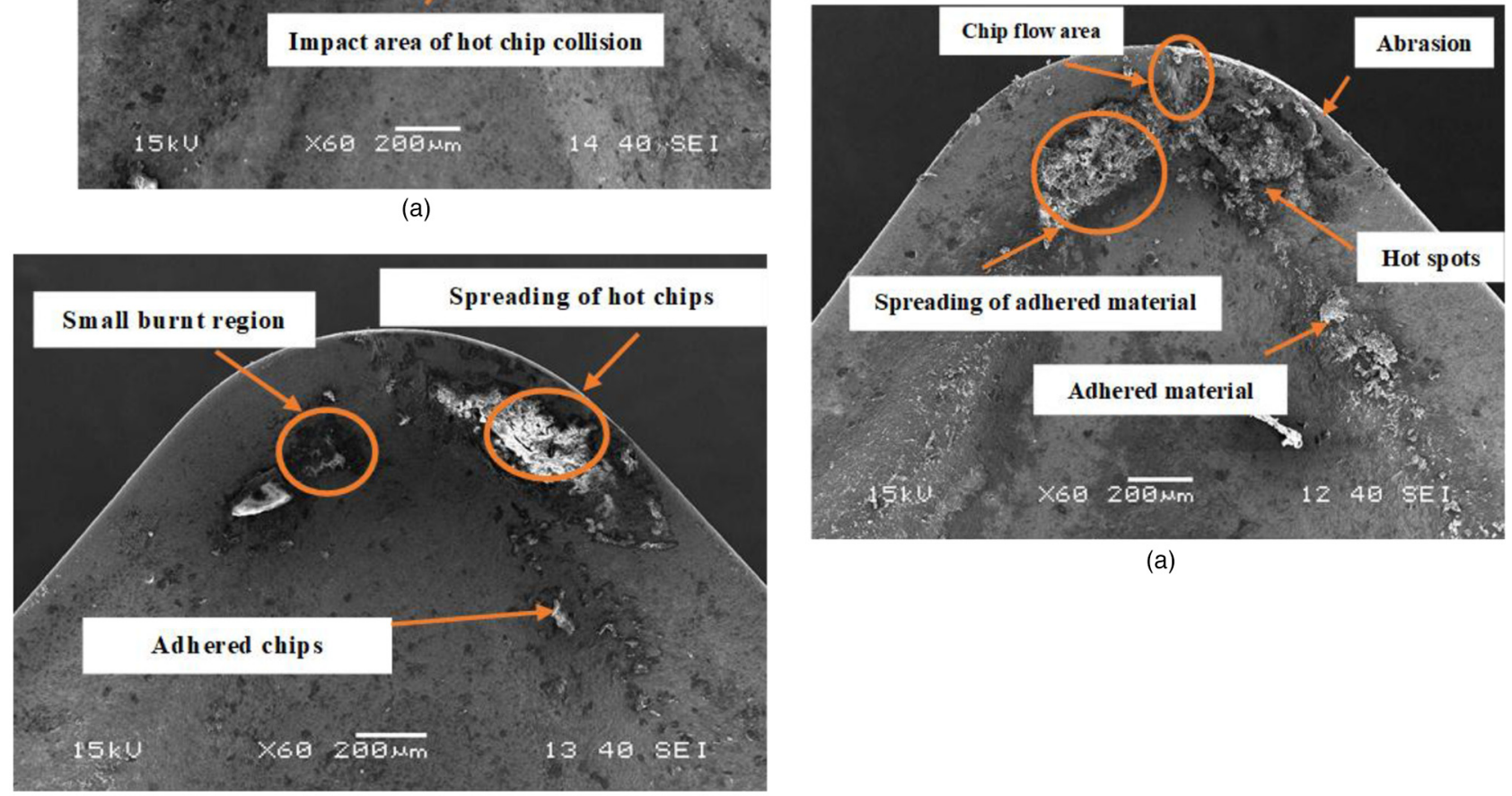

(a)

(c)

Fig. 12. Crater wear of cermet inserts: (a) uncoated and untreated cermet, (b) uncoated and cryo treated cermet, and (c) uncoated and cryo-treated with tempered cermet.

diffusion or chemical reaction between the workpiece and tool material. Because of high temperatures that was generated at the tool-chip and tool-work interfaces during machining, the migration of atoms occurs from the workpiece and tool material. The adhesion of workpiece material on the tool rake face was observed for untreated, cryo-treated and cryo-treated with tempered inserts.

At the rake face of the uncoated and untreated cermet insert, thick abrasion marks due to hard chip flow and adhered chip materials were noticed along with edge chipping. Due to the sliding action of hot chips, black spots were observed at the contact area as shown in Figure 12a. Further, it was observed from the SEM image that because of hot chip collision the respective area was deteriorated. This happened mainly because of low thermal conductivity, less hardness and wear resistance of UCUT cermet insert. Similarly, for uncoated and cryo-treated cermet insert, thin abrasion marks and adhered workpiece materials were observed along with very few hot spots on the rake face. Nevertheless, one interesting phenomenon called spreading of adhered material was detected on the rake face of the insert as shown in Figure 12b. Throughout the continuous turning operation, hot chips were produced, but these hot chips could not damage the rake surface of the cryo-treated insert due to high thermal conductivity and better hot hardness. Whereas, due to segregation of high volume of hot chips and generation of high temperature at the tool-chip contact zone, melting of chips occurred on the rake face resulting in spreading of materials. The same phenomenon was also observed for cryo-treated and tempered insert and a very small burnt region was found (Fig. 12c). Chipping and fracture were not observed for this insert because of high wear resistance and increment of toughness.

\subsection{Chip morphology}

Chip morphology plays an important role in hard machining. Both the surface quality and the tool life highly depend upon the chip morphology. At higher feed rate, the chip was entwined and formed a serrated type saw 


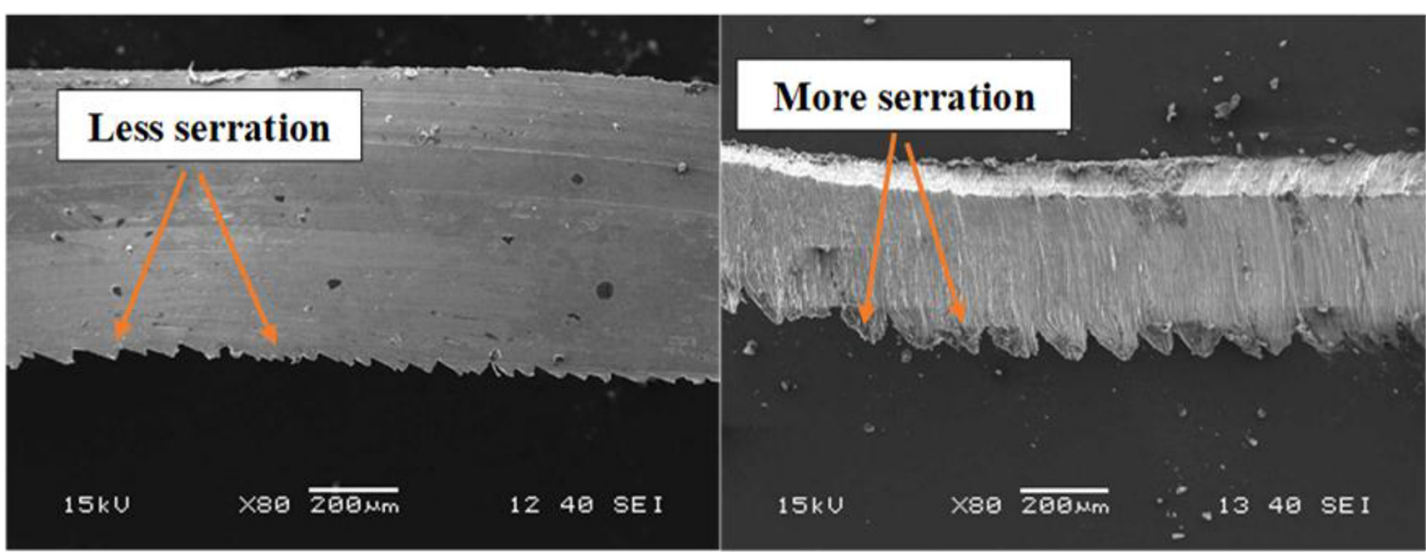

(a)

(b)

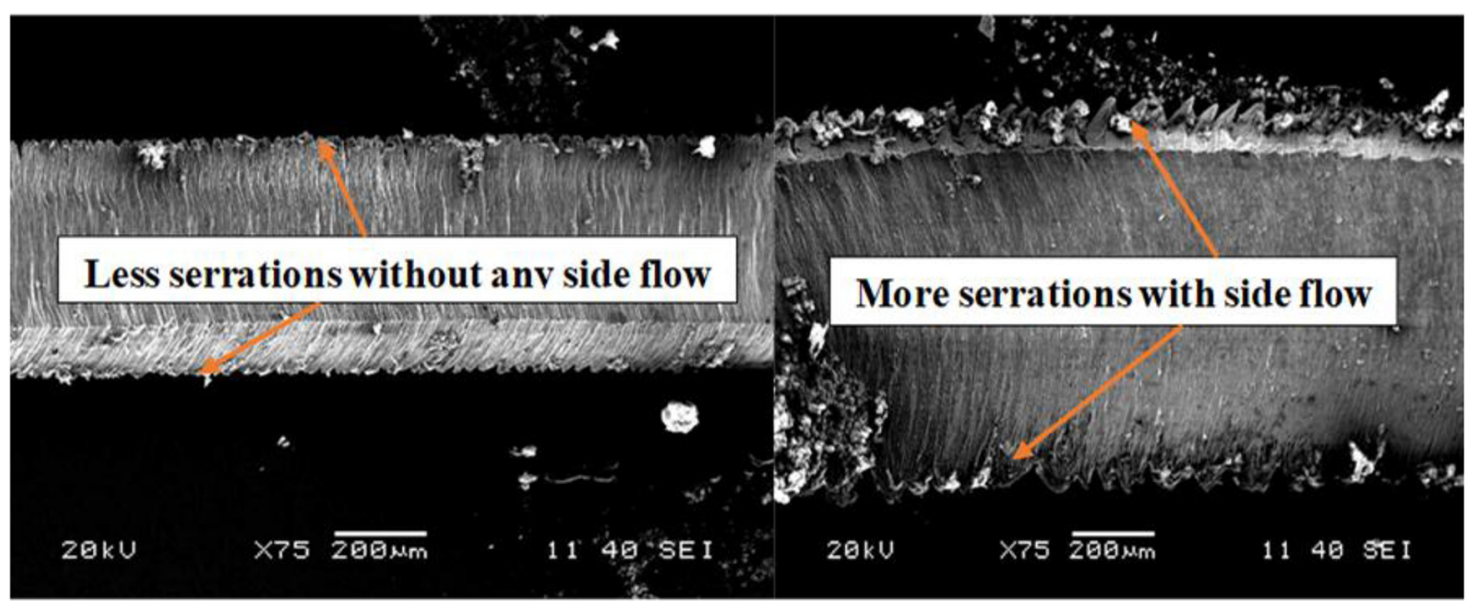

(c)

(d)

Fig. 13. Images of chips procured by Field Emission Scanning Electron Microscope (FESEM) after machining hardened alloy steel with (a, c) cryo-treated and tempered tools, and (b, d) uncoated and untreated tools.

tooth on the chip surface, which was mainly due to severe plastic deformation at primary and secondary shear zones. Also, due to higher feed, the increase in the contact length between chip and tool resulted in high heat generation due to which microstructural alteration and thermal deformation occurred. This was the main reason for the formation of saw tooth chip. Highest flank wear was observed for UCUT cermet while lowest flank wear was observed for UCDCTT cermet insert because of its good strength, high microhardness, improved toughness and wear resistance which resulted in smaller saw tooth on the chip surface as shown in Figure 13. Due to maximum flank wear, more heat was generated that contributes to wider saw tooth chip for UCUT insert illustrated in Figure 13b. Another important attribute of chip morphology was discerned during this present experimental investigation called side flow of chips. With UCDCTT insert, no side flow of chip was observed (Fig. 13c), whereas with UCUT insert severe material side flow was observed, which was shown in Figure 13d. A notable improvement in microhardness, wear resistance and toughness for UCDCTT insert after cryogenic treatment and tempering might be contributed to this.

\subsection{Economic feasibility in hard turning using various types of uncoated cermet inserts}

The fundamental venture of any manufacturing process is to produce a component at the minimum cost possible. Nowadays, with increased burden on cost management and profitability, manufacturers have aimed to regulate the overall cost for machining operations in order to confirm consistency and establish cost benchmarks for recommendation in coming times. The total machining cost has three major constituents: machining cost, cutting tool changing cost (idle time cost) and cutting tool cost. Longer tool life results high machining cost because of the cost of using the machine and operator for an extrapolated machining time while, a shorter tool life leads to high production cost because of frequent tool replacement (tool cost and tool changing cost). Therefore, a detailed 


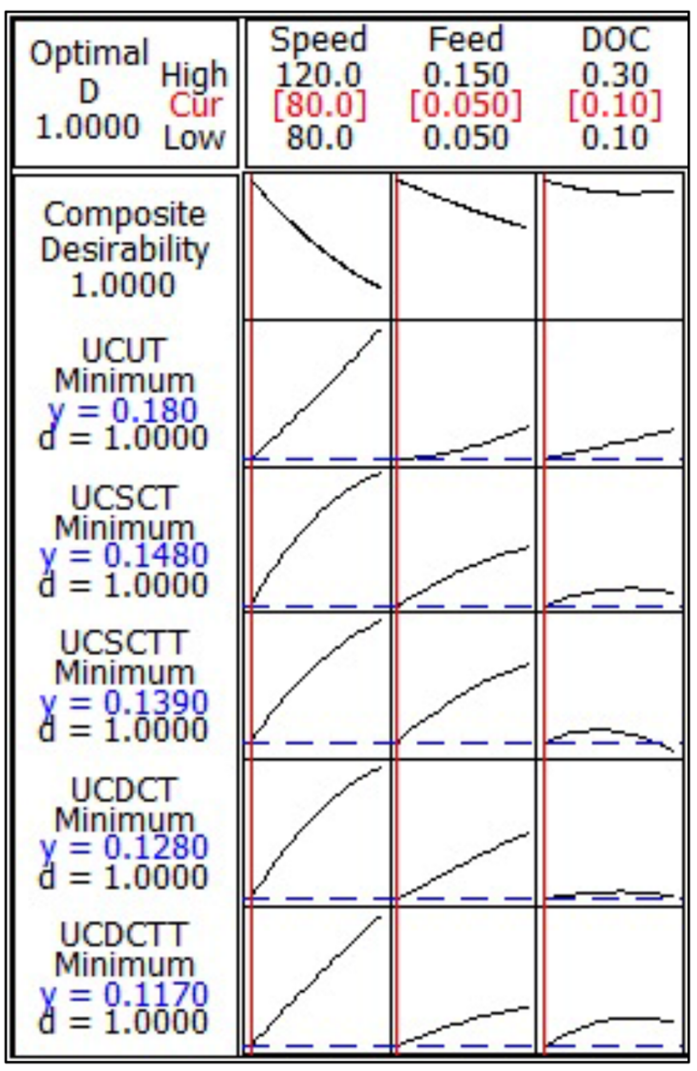

Fig. 14. Optimization plot of flank wear using RSM for different cermet inserts.

economic analysis is needed in order to maintain a balance in the aforementioned trends. Concerning for economical estimation and cost consciousness, the selection of process parameters appropriate to an optimum range leads to a paradoxical enhancement in tool life. In addition, to investigate whether a cryogenic treatment could be an economically feasible process for hard turning operation using various cermet inserts at optimal setting of cutting parameters, tool life evaluation is mandatory. Hence, in the present work, desirability function analysis of response surface methodology is performed to obtain the optimum cutting condition for tool life evaluation. Figure 14 exhibits the optimization results, which presented the optimal solution for minimum tools flank wear $(\mathrm{VB})$ value at cutting speed $=80 \mathrm{~m} / \mathrm{min}$, feed $=$ $0.05 \mathrm{~mm} / \mathrm{rev}$ and $\mathrm{doc}=0.10 \mathrm{~mm}$.

Finally, some additional experiments are conducted under the pre-cited optimal parametric condition, which reported the life of the different uncoated cermet inserts such as UCUT, UCSCT, UCSCTT, UCDCT and UCDCTT are about 22, 2833,41 , and $47 \mathrm{~min}$ respectively, keeping in mind the tool life criterion (VB $\leq 0.3 \mathrm{~mm}$ ) during HT process. The progression of flank wear of various cermet inserts (UCUT, UCSCT, UCSCTT, UCDCT, and UCDCTT) with respect to machining time are illustrated in Figure 15. In considering the life of coated ceramic tool being evaluated, a cost analysis has been proposed according to Gilbert's strategy of machining economics [27-30]. A general procedure of estimating the total cost per piece for proposed work material and different uncoated cermet tool inserts in FDHT condition is described in Table 6 . On the basis of single cutting edge, the approximate total machining cost per part using different uncoated cermet inserts are Rs. 51.39 for UCUT, Rs. 51.59 for UCSCT, Rs. 49.33 for UCSCTT, Rs. 49.15 for UCDCT, and Rs. 47.40 in case of UCDCTT (all prices in Indian rupees). So, from the above cost analysis, it was observed that UCDCTT cermet insert was the most economical one compared to other cermets due to its higher tool life for which down time reduced. So, the above analysis clearly indicated that it was beneficial to carry out the hard turning operation with UCDCTT cermet insert at the optimal combination of machining variables. Moreover, deep cryogenic treatment with tempering was a better alternative for the tool life enhancement.

\section{Conclusions}

In this present experimental investigation, hard turning was performed on 4340 alloy steel at $48 \mathrm{HRC}$ using UCUT, UCSCT, UCSCTT, UCDCT and UCDCTT cermet inserts and the performances of these inserts in terms of cutting force, flank wear, crater wear, chip morphology and surface roughness were studied. Moreover, economic feasibility for the current study was also accomplished using these inserts. Following remarkable conclusions were drawn from the current experimental work.

- All the machining characteristics such as cutting force, flank wear, crater wear and surface roughness were found to be minimum in case of UCDCTT cermet insert compared to other four cermet inserts.

- As a result of cryogenic treatment, cutting forces decreased and surface roughness improved in parallel with improvements in the wear resistance of cutting tools.

- The cutting tool after cryogenic treatment presents relatively strong wear resistance in hard turning process due to enhanced thermal and other mechanical properties, which results in enhancing the tool life of the cutting inserts up to some extent for all the three cutting speed tested. An increased wear was noticed in the untreated cutting tool as compared with cryogenic treated one. It was observed from the results that the utilization of a cryogenically treated cutting tool insert helps in improving the tool life.

- Cryogenic treatment of cutting inserts causes crystal structure changes in both the hard and the soft binder phases of titanium carbide which, along with the precipitation of carbides, may be responsible for the enhanced cutting life.

- Tempering treatments are conducted after heat treatment in order to eliminate internal stresses in the tool material which occur due to excessive cooling during 
(a) Growth of flank wear for UCUT insert

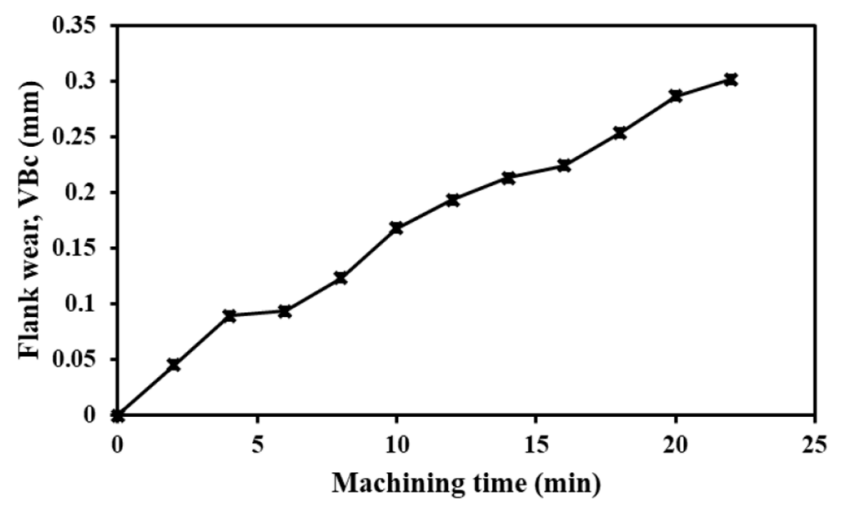

(c) Growth of flank wear for UCSCTT insert

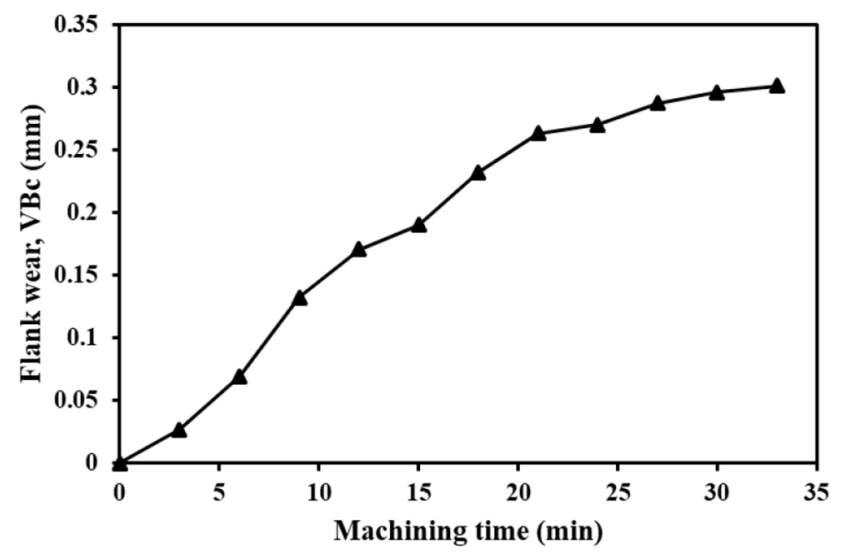

(b) Growth of flank wear for UCSCT insert

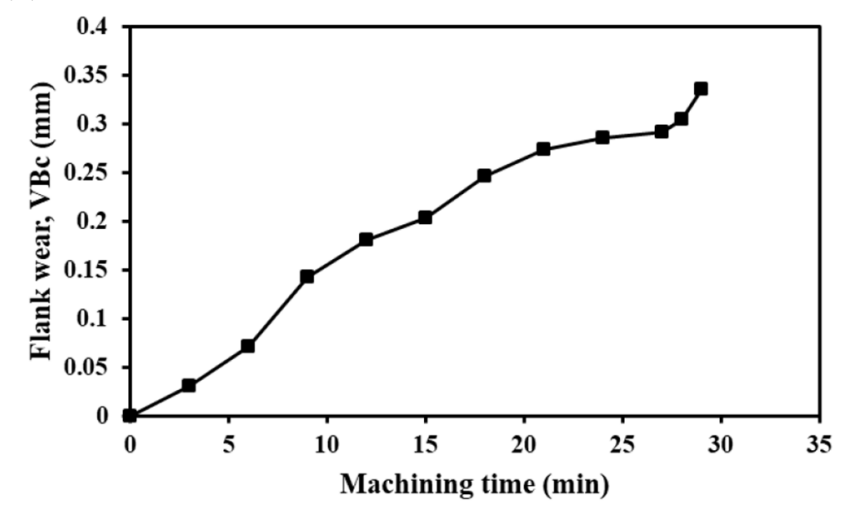

(d) Growth of flank wear for UCDCT insert

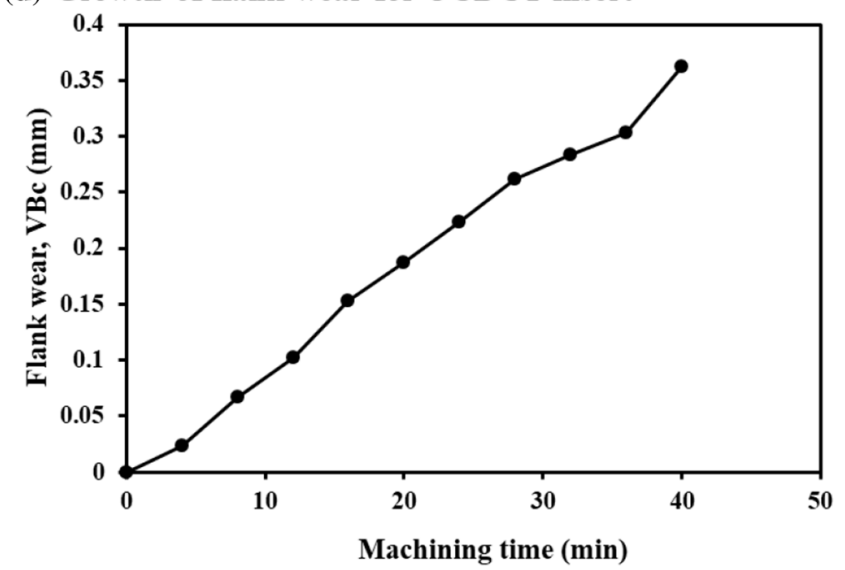

(e) Growth of flank wear for UCDCTT insert

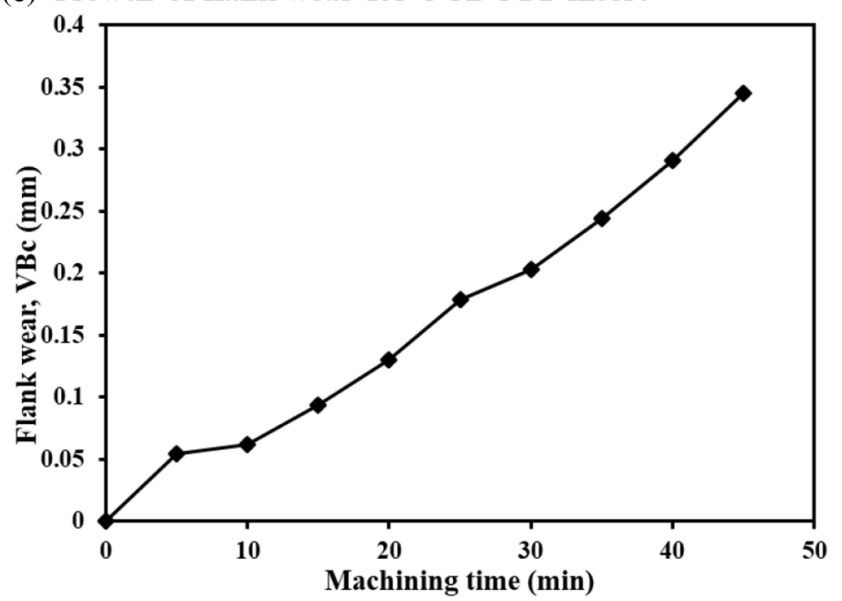

Fig. 15. Development of flank wear of different cermet inserts with machining time at optimum cutting conditions.

cryogenic treatment. These treatments were found to contribute to cutting tool performance.

- Chip formation process was greatly affected by cryogenic treatment. Serrations and material side flow were the two primary properties of chips found. With deep cryotreated and tempered inserts, very less serrations and no side flow were observed compared to untreated inserts.
- Hardness enhanced substantially for cryo-treated insert compared to untreated one and with tempering excessive hardness was reduced also.

- Machining with optimal input parameters reduced the cost effectively. The total machining cost for UCDCTT insert was found to be the least i.e. Rs 47.40 among all other inserts. 
Table 6. Comparisons of machining cost in hard turning of AISI 4340 steel with different cermet tools.

\begin{tabular}{|c|c|c|c|c|c|c|}
\hline No. & Costs & UCUT & UCSCT & UCSCTT & $\mathrm{UCDCT}$ & UCDCTT \\
\hline 3 & $\begin{array}{l}\text { Tool changing cost per piece } \\
{\left[x T d\left(T_{m} / T\right)\right]}\end{array}$ & Rs. 6.54 & Rs. 5.14 & Rs. 4.36 & Rs. 3.51 & Rs. 3.06 \\
\hline 4 & Cutting insert cost per piece & Rs. 450 & Rs. 450 & Rs. 450 & Rs. 450 & Rs. 450 \\
\hline 6 & Average value of single cutting edge $(y)$ & Rs. 112.5 & Rs. 157.5 & Rs. 170 & Rs. 220 & Rs. 230 \\
\hline 7 & $\begin{array}{l}\text { Machining cost per piece over tool life } \\
{\left[y\left(T_{m} / T\right)\right]}\end{array}$ & Rs. 16.06 & Rs. 17.66 & Rs. 16.18 & Rs. 16.85 & Rs. 15.37 \\
\hline 8 & Total machining cost per piece, $(2+3+7)$ & Rs. 51.39 & Rs. 51.59 & Rs. 49.33 & Rs. 49.15 & Rs. 47.40 \\
\hline
\end{tabular}

- Application of finish dry hard turning (FDHT) not only can eliminate cutting fluid but also substantial technological, ecological and economical benefits as has been observed in machining hardened AISI 4340 steels by different uncoated cermet tool inserts.

\section{Nomenclature}

$\begin{array}{ll}d & \text { Depth of cut (mm) } \\ f & \text { Feed (mm/revolution) } \\ \text { Fz } & \text { Tangential cutting force (N) } \\ \text { HRC } & \text { Rockwell hardness in C scale } \\ L & \text { Machining length (mm) } \\ r & \text { Nose radius (mm) } \\ \text { SEM } & \text { Scanning electron microscope } \\ v & \text { Cutting speed (m/min) } \\ \text { VBc } & \text { Flank wear of inserts (mm) } \\ \text { UCUT } & \text { Uncoated and untreated } \\ \text { UCSCT } & \text { Uncoated and shallow cryo-treated } \\ \text { UCSCTT } & \text { Uncoated and shallow cryo-treated with } \\ & \text { tempered } \\ \text { UCDCT } & \text { Uncoated and deep cryo-treated } \\ \text { UCDCTT } & \text { Uncoated and deep cryo-treated with tem- } \\ & \text { pered } \\ \alpha_{\mathrm{o}} & \text { Clearance angle (o) } \\ \gamma_{\mathrm{o}} & \text { Rake angle (o) }\end{array}$

\section{References}

[1] R. Thornton, T. Slatter, R. Lewis, Effects of deep cryogenic treatment on the wear development of H13A tungsten carbide inserts when machining AISI 1045 steel, Prod. Eng. 8, 355-364 (2013)

[2] K. Vadivel, R. Rudramoorthy, Performance analysis of cryogenically treated coated carbide inserts, Int. J. Adv. Manuf. Technol. 42, 222-232 (2008)
[3] S.S. Gill, R. Singh, H. Singh, J. Singh, Wear behaviour of cryogenically treated tungsten carbide inserts under dry and wet turning conditions, Int. J. Mach. Tools Manuf. 49, 256$260(2009)$

[4] T.V. SreeramaReddy, T. Sornakumar, M. VenkataramaReddy, R. Venkatram, Machinability of C45 steel with deep cryogenic treated tungsten carbide cutting tool inserts, Int. J. Refract. Metals Hard Mater. 27, 181-185 (2009)

[5] T.V.S. Reddy, T. Sornakumar, M.V. Reddy, R. Venkatram, A. Senthilkumar, Turning studies of deep cryogenic treated P-40 tungsten carbide cutting tool inserts - technical communication, Mach. Sci. Technol. 13, 269-281 (2009)

[6] S.S. Gill, H. Singh, R. Singh, J. Singh, Flank wear and machining performance of cryogenically treated tungsten carbide inserts, Mater. Manuf. Process. 26, 1430-1441 (2011)

[7] S.S. Gill, J. Singh, H. Singh, R. Singh, Investigation on wear behaviour of cryogenically treated TiAlN coated tungsten carbide inserts in turning, Int. J. Mach. Tools Manuf. 51, 2533 (2011)

[8] M. Dogra, V.S. Sharma, A. Sachdeva, N.M. Suri, J.S. Dureja, Performance evaluation of CBN, coated carbide, cryogenically treated uncoated/coated carbide inserts in finishturning of hardened steel, Int. J. Adv. Manuf. Technol. 57, $541-553$ (2011)

[9] M.C. Kumar, P. VijayaKumar, B. Narayan, Effect of deep cryogenic treatment and double tempering on machinability and tool life of HSS tool, Int. J. Artif. Intell. Mechatron. 1, $147-150(2013)$

[10] H.-B. He, W.-Q. Han, H.-Y. Li, D.-Y. Li, J. Yang, T. Gu, T. Deng, Effect of deep cryogenic treatment on machinability and wear mechanism of TiAlN coated tools during dry turning, Int. J. Precision Eng. Manuf. 15, 655-660 (2014)

[11] N.A. Özbek, A. Çiçek, M. Gülesin, O. Özbek, Investigation of the effects of cryogenic treatment applied at different holding times to cemented carbide inserts on tool wear, Int. J. Mach. Tools Manuf. 86, 34-43 (2014)

[12] N.S. Kalsi, R. Sehgal, V.S. Sharma, Effect of tempering after cryogenic treatment of tungsten carbide-cobalt bounded inserts, Bull. Mater. Sci. 37, 327-335 (2014) 
[13] M. Strano, P. Albertelli, E. Chiappini, S. Tirelli, Wear behaviour of PVD coated and cryogenically treated tools for Ti-6Al-4V turning, Int. J. Mater. Form. 8, 601-611 (2015)

[14] R.G. Deshpande, Machining C-45 steel with cryogenically treated and microwave irradiate tungsten carbide cutting tool inserts, Int. J. Innov. Res. Sci. Eng. Technol. 4, 339-345 (2015)

[15] J. Singh, P. Singh, H. Singh, Flank wear evaluation of cryogenically treated ISO K313 WC/Co inserts in dry CNC turning of 2507 super-duplex stainless steel, Int. J. Mech. Prod. Eng. 3, 30-37 (2015)

[16] S. Akıncioglu, H. Gökkaya, I. Uygur, The effects of cryogenic-treated carbide tools on tool wear and surface roughness of turning of Hastelloy C22 based on Taguchi method, Int. J. Adv. Manuf. Technol. 82, 303-314 (2015)

[17] N.A. Özbek, A. Çiçek, M. Gülesin, O. Özbek, Effect of cutting conditions on wear performance of cryogenically treated tungsten carbide inserts in dry turning of stainless steel, Tribol. Int. 94, 223-233 (2016)

[18] M. Dhananchezian, M. Pradeep Kumar, Cryogenic turning of the $\mathrm{Ti}-6 \mathrm{Al}-4 \mathrm{~V}$ alloy with modified cutting tool inserts, Cryogenics 51, 34-40 (2011)

[19] D. Umbrello, F. Micari, I.S. Jawahir, The effects of cryogenic cooling on surface integrity in hard machining: a comparison with dry machining, CIRP Ann 61, 103-106 (2012)

[20] S. Ravi, M.P. Kumar, Experimental investigation of cryogenic cooling in milling of AISI D3 tool steel, Mater. Manuf. Process. 27, 1017-1021 (2012)

[21] Al-K.A. Ghamdi, A. Iqbal, G. Hussain, Machinability comparison of AISI 4340 and Ti-6Al-4V under cryogenic and hybrid cooling environments: a knowledge engineering approach, Proc. Inst. Mech. Eng. B J. Eng. Manuf. 229 , 2144-2164 (2014)

[22] A.K. Islam, M. Mia, N.R. Dhar, Effects of internal cooling by cryogenic on the machinability of hardened steel, Int. J. Adv. Manuf. Technol. 90, 11-20 (2016)

[23] M. Mia, Multi-response optimization of end milling parameters under through-tool cryogenic cooling condition, Measurement 111, 134-145 (2017)

[24] M. Jamil, A.M. Khan, H. Hegab, L. Gong, M. Mia, M.K. Gupta, N. He, Effects of hybrid Al2O3-CNT nanofluids and cryogenic cooling on machining of Ti-6Al-4V, Int. J. Adv. Manuf. Technol. 102, 3895-3909 (2019)

[25] P.J. Ross, Taguchi techniques for quality engineering, 2nd edn. McGraw-Hill, New York, 1996

[26] D. Senthilkumar, I. Rajendran, Influence of shallow and deep cryogenic treatment on tribological behavior of En 19 steel, J. Iron Steel Res. Int. 18, 53-59 (2011)

[27] M.C. Shaw, Metal cutting principles, 2nd edn. Oxford University Press, New York, 2005, p. 449

[28] A.S. More, W. Jiang, W.D. Brown, A.P. Malshe, Tool wear and machining performance of CBN-TiN coated carbide inserts and PCBN compact inserts in turning AISI 4340 hardened steel, J. Mater. Process. Technol. 180, 253-262 (2006)

[29] S.R. Das, A. Panda, D. Dhupal, Analysis of surface roughness in hard turning with coated ceramic inserts: Cutting parameters effects, prediction model, cutting conditions optimization and cost analysis', Ciência e Técnica Vitivinícola: Sci. Technol. J. 32, 127-154 (2017)

[30] A. Panda, S.R. Das, D. Dhupal, Surface roughness analysis for economical feasibility study of coated ceramic tool in hard turning operation, Process Integr. Optim. Sustain. 1, 237$249(2017)$

Cite this article as: A. Das, S.R. Das, S.K. Patel, B.B. Biswal, Experimental investigation of various machining attributes and cost estimation during machining of hardened AISI 4340 steel with untreated and cryo treated cermet inserts, Mechanics \& Industry $\mathbf{2 1}, 110(2020)$ 